\title{
Aprendizagem Tecnológica e Inovação Industrial em Economias Emergentes: uma Breve Contribuição para o Desenho e Implementação de Estudos Empíricos e Estratégias no Brasil*
}

\author{
Paulo N. Figueiredo
}

Escola Brasileira de Administração Pública e de Empresas / Fundação Getúlio Vargas

\section{RESUMO}

O tema estratégia de inovação industrial entrou formalmente na agenda de discussão e ação governamental no Brasil no final dos anos 1960. Desde então, tem havido uma profusão de estudos baseados em descrições, análises e propostas relativas a estratégias de inovação industrial no País. A despeito do grande mérito dos vários trabalhos neste campo no Brasil, ainda há uma escassez de contribuições conceituais e, principalmente, gerenciais voltadas para o aprimoramento do desenho e da implementação de estudos empíricos e de tais estratégias. Por isso, este artigo tem seu foco em duas tarefas: a primeira é clarificar certas definições relativas ao desenho e implementação de estudos empíricos e de estratégias de inovação industrial a partir da perspectiva de aprendizagem tecnológica no contexto de economias emergentes; a segunda é apresentar métricas

\footnotetext{
Este artigo foi produzido no âmbito do Programa de Pesquisa em Aprendizagem Tecnológica e Inovação Industrial no Brasil, da Escola Brasileira de Administração Pública e de Empresas (EBAPE), da Fundação Getulio Vargas (FGV). Sou profundamente grato ao Prof. Dr. Bianor Scelza Cavalcanti, diretor da EBAPE, pelo seu constante incentivo ao fortalecimento desse Programa de Pesquisa e pela sua leitura atenta, comentários encorajadores e importantes sugestões à versão inicial deste artigo. Também sou imensamente grato à Dra. Conceição Vedovello, da Financiadora de Estudos e Projetos (FINEP), pela sua leitura cuidadosa e seus valiosos comentários sobre a versão anterior deste texto. Agradeço também aos quatro avaliadores anônimos da Revista Brasileira de Inovação pelos seus comentários detalhados e extremamente úteis. Dedico este artigo a Martin Bell (SPRU/Sussex University), meu professor e mentor, que inspira meus contínuos esforços de pesquisa sobre o intricado processo de aprendizagem tecnológica em economias emergentes.
} 
associadas à operacionalização de tais estudos e estratégias, particularmente no Brasil. Espera-se com isso contribuir para ampliar a compreensão sobre o intricado processo de desenvolvimento tecnológico na indústria, no contexto de economias emergentes e, assim, auxiliar pesquisadores e gestores envolvidos com a gestão da inovação industrial no Brasil.

Palavras-Chave | Aprendizagem Tecnológica; Estratégia de Inovação Industrial; Economias Emergentes; Métricas

Códigos JEL | O14, O32, O38

\section{ABSTRACT}

The theme of industrial innovation strategies was formally brought into the government agenda in Brazil during the late-1960s. Since then, there has been a profusion of studies based on descriptions and analysis relative to the design and implementation of industrial innovation strategies. Despite the merit of the existing works in this field in Brazil, there still is a scarcity of both conceptual and, in particular, management approaches to contribute to improving innovation strategies in Brazil. Thus, the focus of this article is centred on two tasks. The first is to clarify some definitions underlying the design and implementation of empirical studies and industrial innovation strategies from the perspective on technological learning in emerging economies. The second is to present some metrics associated with the design and implementation of such strategies and empirical studies, particularly in Brazil. The article seeks to clarify and enlarge the understanding of the intricate process of technological development in the context of emerging economies and, thus, assist researchers and managers involved with industrial innovation management in Brazil.

KEYWORDS I Technological Learning; Industrial Innovation; Emerging Economies; Metrics

JEL CODES $\mid$ O14, O32, O38 


\section{Introdução}

A política tecnológica entrou formalmente na agenda de discussão e ação governamental no Brasil no final dos anos 1960 a partir da elaboração do I Plano Nacional de Desenvolvimento (PND, 1972/74) e do Plano Básico de Desenvolvimento Científico e Tecnológico (PBDCT, 1973/74) seguidos do II e do III PBDCTs. Embora tenham sido publicados há mais de 30 anos, esses planos contêm idéias e proposições que, conforme S. Salles-Filho, em seus recentes artigos publicados na Revista Brasileira de Inovação (ver Salles-Filho, 2002, 2003), aparecem com freqüência nos textos atuais. A partir do início da década de 1990 houve uma profusão de estudos baseados em "diagnósticos", descrições, análises e propostas relativas ao desenho, redesenho e implementação de política tecnológica no Brasil orientada para a inovação, desenvolvimento econômico e inserção da economia brasileira no mercado internacional (ver, p. ex., Marcovitch, 1990; Meyer-Stamer, 1995; Amann \& Baer, 1999; Mani, 2001; Nicolsky, 2001; IEDI, 2002, 2003; Alário-Junior \& Oliveira, 2000; Staub, 2002).

No início da década de 1990 destacam-se os importantes e pioneiros estudos sobre a competitividade de setores industriais da economia brasileira que geraram o importante documento Estudo da competitividade da economia brasileira (ver Coutinho et al., 1993). Não obstante os méritos desses estudos, uma de suas limitações - e, particularmente, deste último - é que não foram implementados à base de modelos analíticos e métricas (ou taxonomias) coerentes. Mais especificamente, tais estudos, particularmente Coutinho et al., 1993, basearam-se muito pouco, ou quase nada, em modelos analíticos centrados no processo de aprendizagem tecnológica e inovação industrial no contexto de empresas de economias emergentes.

Durante o final da década de 1990, o governo federal, por meio do Ministério da Ciência e Tecnologia, liderou uma meritória iniciativa de sistematizar, de maneira detalhada e exaustiva, os vários elementos relacionados ao sistema de Ciência, Tecnologia e Inovação (C,T\&I) considerados necessários ao desenvolvimento nacional, através da edição do documento Ciência, Tecnologia e Inovação: desafio para a sociedade brasileira - Livro verde (Brasil, 2001). Em setembro de 2001, como resultado da Conferência Nacional de C,T\&I, foi gerado o Livro branco da ciência, tecnologia e inovação, cujo objetivo é "apontar 
caminhos para que a C,T\&I possam contribuir para a construção de um País mais dinâmico, competitivo e socialmente mais justo" (Brasil, 2002:21) para o período 2002-2012.

Considerando os vários esforços mencionados acima, é pertinente a afirmação de Salles-Filho $(2002,2003)$ de que alguns dos temas referentes à interação entre C,T\&I e desenvolvimento nacional têm sido recorrentes no debate brasileiro nos últimos 30 anos. Por isso, como argumenta esse autor, em vez de simplesmente apontarmos as dificuldades em resolver questôes já superadas em outros países, precisamos buscar explicações para tal descompasso que, em sua opinião, é de natureza organizacional e institucional.

Porém, indo um pouco mais além, uma das razões-chave para tal descompasso parece ser, principalmente, de natureza de gestão. Por isso, é necessário avançarmos da mera constatação para a busca de elementos pragmáticos que possam contribuir para a materialização bem-sucedida das várias propostas e idéias geradas sobre o aprimoramento do sistema de C,T\&I no Brasil ao longo dos anos.

Em outras palavras, não obstante o grande mérito dos vários "diagnósticos", propostas e estudos existentes (alguns dos quais já mencionados), há uma escassez de contribuições de natureza não apenas conceitual, mas, principalmente gerencial voltadas para o aprimoramento de estratégias de inovação industrial no Brasil. Levando-se em conta o princípio básico de gestão segundo o qual se pode gerir com eficácia aquilo que se pode medir, este artigo concentra-se em duas tarefas: a primeira é esclarecer certas definições relativas a estudos empíricos e ao desenho e implementação de estratégias de inovação industrial a partir da perspectiva de aprendizagem tecnológica no contexto de economias emergentes; a segunda é apresentar métricas associadas à operacionalização de tais estratégias e estudos, particularmente no Brasil. Espera-se com isso contribuir para ampliar a compreensão sobre o intricado processo de desenvolvimento tecnológico na indústria no contexto de economias emergentes e, assim, auxiliar estudiosos e gestores envolvidos com o tema da gestão da inovação industrial no Brasil.

Convém ressaltar que, a despeito dos argumentos que advogam a irrelevância ou ausência de estratégia industrial para o desenvolvimento e crescimento da economia brasileira, evidências ao longo da história e, principal- 
mente, durante as últimas décadas, relativas a países que têm alcançado e sustentado taxas significativas de crescimento e de desenvolvimento industrial e econômico indicam o contrário: tem havido nesses países uma explícita estratégia industrial - com forte ênfase em desenvolvimento tecnológico - que tende a convergir com os objetivos da política macroeconômica. Mais especificamente, e colocado aqui de maneira simples, a agenda de política macroeconômica, em vez de centrar-se tão-somente em aspectos monetários, fiscais e cambiais, também incorpora, com semelhante grau de importância, estratégias de desenvolvimento industrial e tecnológico. Em outras palavras, verifica-se um esforço de convergência entre elementos da política macroeconômica e os da política industrial e tecnológica. Por isso, embora possa parecer óbvio, é preciso alertar que, ainda que se tenha uma política tecnológica - e industrial - bem desenhada, seus resultados serão medíocres se esta divergir da política macroeconômica. ${ }^{1}$

A partir dessa seção introdutória, na Seção 2 são apresentadas as definições de aprendizagem e capacidade tecnológica, no contexto de economias emergentes. A acumulação de capacidade tecnológica como tarefa crítica para empresas que operam em economias emergentes é abordada na Seção 3. Na Seção 4 são apresentadas algumas métricas disponíveis na literatura recente, para auxiliar estudos empíricos e o desenho e implementação de estratégias de inovação industrial. Também são mencionados os estudos no quais essas métricas foram empiricamente aplicadas. Finalmente, na Seção 5 apresentam-se os comentários finais e recomendaçóes deste artigo.

As Seções 2 e 3 caracterizam-se por uma ênfase conceitual. Isso pode parecer por demais "acadêmico". Porém, é preciso considerar que, ao longo dos últimos anos, tem havido uso indiscriminado de certos termos - tanto no discurso como em documentos acadêmicos, governamentais e de consultoria, relacionados a estratégias de inovação industrial - sem uma adequada fundamentação analítica e empírica. Tal prática pode deturpar e interferir negativamente no processo de desenho e implementação de estratégias de inovação industrial, tanto em nível governamental como empresarial. Por isso, opta-se aqui por apresentar as definições e métricas - foco deste documento - a partir de sua base analítica e empírica.

\footnotetext{
Há uma vasta literatura internacional sobre esse assunto produzida desde a década de 1950.
} 


\section{Aprendizagem e capacidade tecnológica: o que são, afinal?}

Costuma-se entender aprendizagem tecnológica em dois sentidos. O primeiro refere-se à trajetória de acumulação de capacidade tecnológica. Essa trajetória pode mudar com o tempo: pode-se acumular capacidades tecnológicas em diferentes direções e a diferentes velocidades. $\mathrm{O}$ segundo sentido diz respeito aos vários processos pelos quais conhecimentos técnicos (tácitos) de indivíduos são transformados em sistemas físicos, processos de produção, procedimentos, rotinas e produtos e serviços da organização. $\mathrm{O}$ termo aprendizagem é aqui entendido neste último sentido. Doravante, entenda-se por aprendizagem o processo que permite à empresa acumular capacidade tecnológica ao longo do tempo.

Várias são as definições de capacidade tecnológica encontradas na literatura. $^{2}$ As mais antigas dizem respeito a uma "atividade inventiva" ou ao esforço criativo sistemático para obter novos conhecimentos em nível da produção (Katz, 1976). A capacidade tecnológica também inclui as aptidões e os conhecimentos incorporados nos trabalhadores, nas instalações e nos sistemas organizacionais, visando mudanças tanto na produção quanto nas técnicas utilizadas (Bell, 1982; Scott-Kemmis, 1988).

Lall (1982, 1987) define capacidade tecnológica como um "esforço tecnológico interno" para dominar novas tecnologias, adaptando-as às condições locais, aperfeiçoando-as e até mesmo exportando-as. Dahlman e Westphal (1982) formularam o conceito de "domínio tecnológico", concretizado através do "esforço tecnológico" para assimilar, adaptar e/ou criar tecnologia. Tal definição é análoga à "capacidade tecnológica" de Bell (1982) e Scott-Kemmis (1988). Aprimorando o conceito, Westphal et al. (1984:5) definem capacidade tecnológica como a "aptidão para usar efetivamente o conhecimento tecnológico". Todas essas definições estão claramente associadas aos esforços internos das empresas no sentido de adaptar e aperfeiçoar a tecnologia por elas

2 Há uma ampla literatura na qual se busca distinguir entre os termos competências e capacidades tecnológicas. Mais precisamente, na língua inglesa os diferentes termos usados são, por exemplo, capabilities, competence, e competencies. Porém, não é o objetivo deste artigo discutir as diferentes perspectivas, mas apresentar a definição mais ampliada do termo capacidade tecnológica no contexto de economias emergentes. Por isso, daqui em diante será usado apenas o termo capacidade tecnológica. Não obstante, é importante lembrar que o termo capacitação tecnológica refere-se ao processo de acumulação de capacidades tecnológicas por meio dos vários processos subjacentes de aprendizagem. 
importada. Tais esforços estão ligados aos aprimoramentos em termos de processos e organização da produção, produtos, equipamentos e projetos técnicos.

De um ponto de vista mais restrito, Pack (1987) entende que a capacidade tecnológica está incorporada em um grupo de indivíduos (p. ex., gerentes, técnicos e engenheiros). Porém, tal definição se mostra demasiado limitada, ignorando o contexto organizacional onde se desenvolvem tais recursos. Para Enos (1991), a capacidade tecnológica envolve o conhecimento técnico (reunido em engenheiros e operadores) e a instituição. Todavia, essa definição, assim como a de Pack, sugere que as pessoas são o locus onde residem as capacidades tecnológicas e que as instituições somente as agregam, mas não as incorporam.

Bell e Pavitt $(1993,1995)$ formularam uma definição mais ampla, segundo a qual a capacidade tecnológica incorpora os recursos necessários para gerar e gerir mudanças tecnológicas. Tais recursos se acumulam e incorporam aos indivíduos (aptidões, conhecimentos e experiência) e aos sistemas organizacionais. Essa definição parece basear-se em outras formuladas anteriormente (p. ex., Katz, 1976; Lall, 1982, 1987; Dahlman \& Westphal, 1982; Bell, 1982; Westphal et al., 1984; Scott-Kemmis, 1988). Além disso, a capacidade tecnológica é de natureza difusa. A partir da "abordagem baseada nos recursos específicos da firma” (Penrose, 1959) e valendo-se de evidências empíricas, Bell (1982) faz distinção entre dois tipos de recursos: os que são necessários para "usar" os sistemas de produção existentes e os que são necessários para "mudar" os sistemas de produção. Estes últimos não devem ser tomados como um conjunto distinto de recursos especializados; por serem de natureza difusa, estão amplamente disseminados por toda a organização.

Em outras palavras, a capacidade tecnológica de uma empresa (ou de um setor industrial) está armazenada, acumulada, em pelo menos, quatro componentes (Lall, 1992; Bell \& Pavitt, 1993, 1995; Figueiredo, 2001): ${ }^{3}$

(a) sistemas técnicos físicos - referem-se à maquinaria e equipamentos, sistemas baseados em tecnologia de informação, software em geral, plantas de manufatura;

(b) conhecimento e qualificação das pessoas - referem-se ao conhecimento

Essa perspectiva ampla para capacidade tecnológica também é encontrada na literatura gestão da inovação no contexto de empresas inovadoras de economias industrializadas (ver, p. ex., Leonard-Barton, 1995). 
tácito, às experiências, habilidades de gerentes, engenheiros, técnicos e operadores que são adquiridos ao longo do tempo, mas também abrangem a sua qualificação formal. Esta dimensão tem sido geralmente denominada de "capital humano" da empresa ou país;

(c) sistema organizacional - refere-se ao conhecimento acumulado nas rotinas organizacionais e gerenciais das empresas, nos procedimentos, nas instruções, na documentação, na implementação de técnicas de gestão (p. ex., total quality management (TQM), material requirement planning (MRP) e outras), nos processos e fluxos de produção de produtos e serviços e nos modos de fazer certas atividades nas organizações;

(d) produtos e serviços - referem-se à parte mais visível da capacidade tecnológica, refletindo conhecimento tácito das pessoas e da organização e os seus sistemas físicos e organizacionais; por exemplo, nas atividades de desenho, desenvolvimento, prototipagem, teste, produção e parte da comercialização de produtos e serviços, estão refletidos os outros três componentes da capacidade tecnológica.

Portanto, existe uma relação inseparável entre esses quatro componentes. Capacidade tecnológica, portanto, possui uma natureza não apenas pervasiva, mas abrangente. Ademais, a capacidade tecnológica é intrínseca ao contexto da firma, região ou país onde é desenvolvida (Penrose, 1959; Dosi, 1988a, 1988b). ${ }^{4}$ Logo, por causa da natureza tácita e ampla da tecnologia - e da capacidade tecnológica -, a dimensão organizacional é, de fato, um componente da tecnologia. Por isso, não se faz aqui distinção entre capacidade tecnológica e organizacional ou entre tecnologia e organização -, já que a última é parte integrante da primeira. Porém, há uma tendência a se negligenciar a dimensão organizacional (e gerencial) da capacidade tecnológica. ${ }^{5}$

4 Logo, é curioso o termo "transferência" de tecnologia. O termo pode transmitir a falsa idéia de que tecnologia pode ser automaticamente transladada de um contexto para outro. No entanto, a real transferência de tecnologia de economias industrializadas para economias emergentes envolve, de um lado, a gestaão da aquisição, instalação e da operação da tecnologia importada. De outro, implica assegurar o engajamento da organização recipiente em um contínuo e sistemático de processo de aprendizagem tecnológica. É justamente essa segunda "metade" que tende a ser negligenciada em estratégias de inovação industrial. Isso contribui para explicar o processo irregular de desenvolvimento tecnológico que ocorre em economias emergentes. Para mais detalhes sobre essa perspectiva ver Bell e Pavitt (1993, 1995) e Bell (1996).

5 Há uma literatura clássica sobre a relação simbiótica entre tecnologia e organização. Ver, p. ex., Rosenberg (1976, 1982), Salomon (1984), Pavitt (1985). 
Ou seja, enquanto grande ênfase costuma ser dada ao "capital humano" como fonte de desenvolvimento tecnológico, inadequada atenção tem sido dedicada ao "capital organizacional". Essas perspectivas limitadas de capacidade tecnológica podem ter implicações práticas importantes para a implementação de estratégias de inovação industrial. Por exemplo, uma das causas de resultados pífios, em termos de desempenho inovador e/ou técnico-econômico da tecnologia importada para a empresa receptora é a "compra" de tecnologia limitada aos sistemas físicos e técnicos.

Em outros casos, ainda que forte atenção possa ser dada ao desenvolvimento de "capital humano" para absorver a tecnologia importada, a dimensão organizacional é normalmente negligenciada. Por exemplo, em atividades de trabalho de campo para pesquisa é comum encontrar gerentes que afirmam que, a despeito da presença de máquinas avançadas e de engenheiros e técnicos altamente qualificados, não se consegue obter inovação em produtos e serviços e não se consegue melhorar o desempenho técnico da empresa. Ou seja, falta uma "organização" para integrar esses elementos. Isso parece refletir a ausência ou inadequação de esforços para aprimorar o tecido organizacional e gerencial onde a capacidade tecnológica da empresa é acumulada.

Por exemplo, Tremblay (1994) examinou uma amostra de fábricas de papel e celulose na Índia e no Canadá e fez uma análise comparativa das dimensões organizacionais da capacidade tecnológica em associação com o aumento da produtividade ao longo do tempo. Entre essas dimensóes organizacionais, incluíam-se: motivação e compromisso com a mudança; comportamento da alta direção; relaçôes cooperativas; processos de tomada de decisão; controle e canal de comunicação; fluxo de informações; interação/influência entre áreas funcionais; tipo de hierarquia; facilidade de uso de recursos na organização e estilo gerencial.

O estudo não encontrou correlação positiva entre aumento da produtividade e capacidade tecnológica em sentido restrito, isto é, incorporada apenas em pessoas e não em sistemas organizacionais. Por outro lado, constatou uma forte associação entre capacidade tecnológica gerida de maneira ampla - ou seja, incorporada nos sistemas organizacionais - e a taxa de crescimento da produtividade das empresas. $\mathrm{O}$ trabalho de Tremblay contribuiu para suprir as limitações de estudos anteriores que procuraram explicar as diferenças internacio- 
nais de produtividade no contexto de economias emergentes com base em uma composição restrita de capacidade tecnológica (p. ex., Pack, 1987).

\section{Acumulação de capacidade tecnológica: tarefa crítica para empresas em economias emergentes}

Uma das características tecnológicas-chave de empresas que operam no contexto de economias emergentes - ou de industrialização recente - é que normalmente iniciam o seu negócio a partir da tecnologia que adquiriram de outras empresas em outros países. Ao iniciarem as suas atividades, não dispõem sequer das capacidades tecnológicas básicas. Para tornarem-se competitivas e aproximarem-se de empresas da "fronteira tecnológica internacional", elas têm que se engajar em um processo de aprendizagem para construir e acumular sua capacidade tecnológica.

Adicionalmente, essas empresas enfrentam outros tipos de desvantagem inicial ao tentar competir em mercados de exportação (Hobday, 1995):

(a) estão normalmente deslocadas das principais fontes internacionais de tecnologia e de pesquisa e desenvolvimento (P\&D), ou seja, a infra-estrutura de tecnologia e inovação em torno da empresa pode possuir carências em termos de recursos físicos, humanos e financeiros; as universidades locais são, geralmente, pouco desenvolvidas;

(b) estão geralmente deslocadas dos principais mercados internacionais para os quais elas desejam fornecer; localizadas em um país em desenvolvimento, essas empresas precisam construir externamente as suas redes de fornecedores e clientes a partir de suas capacidades tecnológicas.

Portanto, uma vez que empresas em economias emergentes geralmente iniciam em condição de não-competitividade no mercado mundial ("infância industrial”), o problema básico da maturidade industrial é acumular capacidade tecnológica para tornar-se e manter-se competitivo nesse mercado (Bell et al., 1984). Tal acumulação envolve uma seqüência evolutiva e cumulativa - de estágios mais simples a complexos (Katz, 1985; Lall, 1992; Bell \& Pavitt, 1995). Empresas que operam em economias emergentes parecem seguir uma trajetória 
FIGURA 1

Trajetórias tecnológicas: empresas de economias industrializadas vs. empresas de economias emergentes

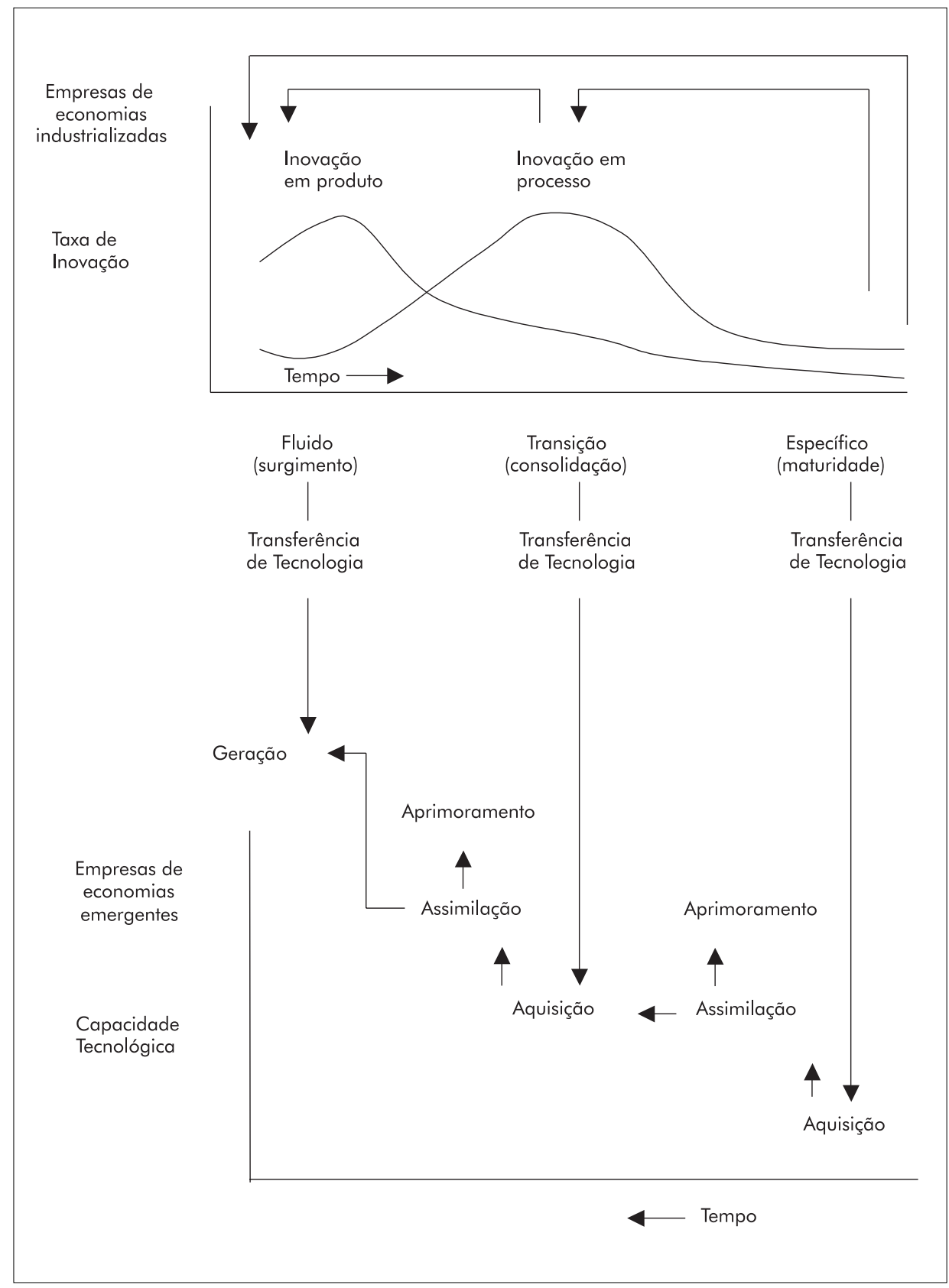

Fonte: Lee et al. (1988); Kim (1997); Utterback (1994). 
diferente das empresas tecnologicamente inovadoras que operam em economias industrializadas: a acumulação de capacidade tecnológica tende a inverter a seqüência "inovação-investimento-produção" - típica de empresas inovadoras de economias industrializadas -, ao seguir trajetória do tipo "produção-investimento-inovação" (Dahlman et al., 1987).

Essa perspectiva alinha-se ao modelo desenvolvido em Kim (1997) que ilustra como esse tipo de empresa segue uma trajetória baseada num modelo de três estágios: aquisição, assimilação e aprimoramento (Figura 1). Durante seu estágio inicial, a ênfase técnica recai sobre a engenharia (E) e, em menor parte, sobre o desenvolvimento (D) e pesquisa (P).

A assimilação bem-sucedida de tecnologia de produção e ênfase crescente em promoção de exportação, juntamente com a crescente capacidade científica e tecnológica local, conduz ao gradual aprimoramento da tecnologia. Ao proceder, ao longo dessa trajetória de aquisição, assimilação e aprimoramento, empresas em economias emergentes invertem a seqüência de P,D\&E de países tecnologicamente avançados

A história nos dá evidências espetaculares sobre o dinamismo tecnológico de empresas e países. Por exemplo, em um passado distante a China exportava tecnologia para a Europa. No século passado, por exemplo, países antes considerados tecnologicamente atrasados tornaram-se líderes tecnológicos mundiais, tais como, Alemanha, Estados Unidos, Japão, Coréia do Sul e Finlândia em indústrias como a de semicondutores, química, farmacêutica, eletrônica de consumo, biológica, automobilística, aço, tecnologia de informação e telefonia móvel.

Logo, é possível começar com o mais baixo nível de capacidade tecnológica e evoluir para níveis muito avançados. Mas isso exige esforços em aprendizagem tecnológica para acelerar a acumulação de capacidades inovadoras, ou seja, capacidades para gerar e gerir mudança tecnológica: das atividades de absorção, adaptação, aprimoramento de tecnologias existentes à geração de tecnologia própria via engenharia, pesquisa e desenvolvimento (E,P\&D). Por quê? A fronteira tecnológica move-se sempre, isto é, é um "alvo" de grande dinamismo. Por isso, uma tarefa crucial para empresas que operam em economias emergentes é acumular capacidade tecnológica a uma velocidade (taxa) mais rápida do que a das empresas que já operam na fronteira tecnológica internacional. Logo, não basta entender apenas se e como o desenvolvimento 
de capacidade tecnológica ocorre em empresas de economias emergentes, mas, principalmente, como acelerá-lo.

\section{Métricas para o aprimoramento do desenho e implementação de estudos empíricos e de estratégias de inovação industrial}

\subsection{Identificação dos tipos e níveis de capacidade tecnológica}

No que concerne à identificação e medição da capacidade tecnológica em empresas ou setores industriais, o que é importante é não apenas identificarmos se esta existe ou não, mas qual a sua natureza e seu nível ou grau. Porém, antes de serem introduzidas as métricas para este fim, são apresentadas a seguir algumas das principais limitações de indicadores convencionais para identificar e medir capacidade tecnológica.

\subsubsection{Indicadores convencionais: por que são limitados?}

Indicadores relativos à $\mathrm{P} \& \mathrm{D}$ e patentes têm sido extensivamente usados para medir a capacidade tecnológica de empresas, setores industriais e países. Isso normalmente envolve a avaliação de capacidades tecnológicas através de pessoal alocado em laboratórios de $P \& D$, gastos em $P \& D$ e da intensidade da atividade de patentes internacionais através de patentes registradas nos Estados Unidos como parâmetro para inovações internacionalmente reconhecidas. ${ }^{6}$

Há uma vasta literatura internacional, concernente ao contexto de empresas e países tecnologicamente avançados, que mede capacidade tecnológica de firmas, indústrias e países, à base, por exemplo, de gastos em P\&D (Mansfield et al., 1979), qualificações formais de indivíduos (Pack, 1987; Jacobsson \& Oskarsson, 1995), investimentos em pessoal alocado em laboratórios de P\&D (Wortman, 1990) e estatísticas de patentes (Patel, 1995). Adicionalmente, o Manual de Oslo (ver OECD, 1997) que, embora tenha avançado em relação ao padrão de medida anterior (Manual Frascati), adota como critério-chave a medição de atividades tecnológicas por meio de estatísticas de P\&D.

6 Discussões detalhadas sobre a limitação desses indicadores para o contexto de empresas em economias emergentes são desenvolvidas em Bell \& Pavitt (1993, 1995); Ariffin \& Bell (1999); Ariffin (2000) e Figueiredo (2001, 2003a, 2003b). 
A combinação de estatísticas de patentes e outras medidas quantitativas, como gastos em P\&D, educação, percentual de cientistas e engenheiros qualificados e intensidade de capital têm sido usados em alguns estudos no Brasil para medir capacidade tecnológica (ver, p. ex., Macedo e Albuquerque, 1999; Quadros et al., 2001; Andreassi \& Sbragia, 2001; Kannebley, 2003). Vale destacar a Pesquisa Industrial de Inovação Tecnológica (PINTEC), realizada pelo Instituto Brasileiro de Geografia e Estatística (IBGE) para o período 1998-2000, em um universo de 72 mil empresas. Tais estudos são extremamente meritórios ao apresentarem uma perspectiva agregada das atividades tecnológicas em empresas no Brasil. Vários deles têm suas raízes na literatura internacional sobre fatores determinantes das atividades inovadoras em nível de empresas (p. ex., Cohen \& Levin, 1989; Cohen \& Levinthal, 1990; Kumar \& Siddharthan, 1997). ${ }^{7}$

Porém, como argumentado em Lall (1992), Bell e Pavitt (1993, 1995), Dutrénit (2000), Ariffin (2000) e Figueiredo (2001, 2003a, 2003b), há situações em que algumas dessas medidas têm suas próprias limitações e são menos relevantes pelas seguintes razões:

(a) indicadores relativos às atividades de P\&D e de patentes são apenas prevalentes em alguns setores industriais de países tecnologicamente avançados (p. ex., os Estados Unidos, Japão e países selecionados da Europa, como Reino Unido e Alemanha), onde certas empresas têm níveis suficientemente profundos de P\&D e intensiva produção de patentes internacionais. Logo, a aplicação desses indicadores para empresas em economias emergentes que, em geral, não possuem níveis sofisticados de capacidade tecnológica inovadora para conduzir atividades de P\&D e patentes seria irrelevante;

(b) estatísticas de patentes internacionais, particularmente patentes nos Estados Unidos, são geralmente aceitas como uma medida superior de capacidade tecnológica. Estão disponíveis para longo período de tempo e fornecem detalhes estatísticos altamente quantificáveis que poderiam ser examinadas de acordo com localização geográfica e área técnica (Patel, 1995). Entretanto, muito embora isso seja verdadeiro, avaliar capacidades

7 Tais fatores envolvem, p. ex., o tamanho da empresa, sua orientação exportadora, origem do capital, estrutura societária, setor industrial ao qual pertence e condições de demanda. Porém, o desenho e o método de tais estudos não captam os fatores intra-organizacionais, como p. ex., os processos de aprendizagem subjacentes à trajetória de acumulação de capacidade tecnológica da empresa. Esse ponto será retomado adiante na Seção 4.3. 
tecnológicas tendo como base as estatísticas internacionais de patentes, particularmente as estatísticas de patentes dos EUA, poderia ser limitante e tendencioso para empresas em economias emergentes que não exportam significativamente produtos especializados e de marca própria para o mercado dos EUA;

(c) nas empresas que operam em economias emergentes, como por exemplo, na América Latina, na Ásia, na África do Sul ou alguns países do Leste Europeu, é rara a incidência de laboratórios de P\&D formalmente estruturados conforme aqueles encontrados em empresas de economias industrializadas. Não obstante, atividades tecnológicas inovadoras e complexas são conduzidas através dos departamentos de engenharia, de qualidade, de manutenção. É muitas vezes nessas unidades organizacionais que estão acumuladas grande parte das capacidades tecnológicas inovadoras das empresas;

(d) a maneira como a empresa constrói a sua base organizacional influencia o sucesso ou o fracasso de seu engajamento em atividades inovadoras - de básicas a P\&D. Porém, as abordagens baseadas em indicadores convencionais não captam as características e elementos do tecido organizacional onde a capacidade tecnológica é desenvolvida, acumulada e sustentada;

(e) outro problema de estudos baseados em estatísticas de indicadores convencionais é que examinam a capacidade tecnológica em um ponto no tempo (momento atual - snap-shot studies). ${ }^{8}$ Tal abordagem estática não permite esclarecer como empresas desenvolveram progressivamente níveis mais profundos de capacidade tecnológica.

\subsubsection{Métrica alternativa para identificar e medir capacidade tecnológica}

Baseando-se nos estudos de Katz (1987), Dahlman et al. (1987) e Lall (1987; 1992; 1994) desenvolveram um modelo no qual as capacidades tecnológicas de uma empresa são categorizadas por funções. Tal modelo sugere que a acumulação se processa das categorias mais simples para as mais complexas. Além disso, "existe um conjunto básico de funções em cada categoria principal 8 É o caso, p. ex., do desenho da PINTEC. 
que deve ser incorporado pela empresa a fim de garantir uma operação comercial bem-sucedida (...). Esse conjunto básico deverá ampliar-se à medida que a empresa for assumindo tarefas mais complexas" (Lall, 1994:267), de tal modo que, nas etapas mais avançadas, ela se tornará uma empresa "tecnologicamente madura". Esta se caracteriza principalmente pela "habilidade de identificar o seu potencial para a especialização eficiente em atividades tecnológicas; de ampliar e intensificar tais atividades; e de recorrer seletivamente a outras empresas a fim de complementar suas próprias capacidades" (Lall, 1994:267, 269). ${ }^{9}$

O princípio dessa métrica começou a ser desenvolvido pelo clássico estudioso russo Alexander Gerschenkron (ver Gerschenkron, 1962). Depois, outro avanço significativo foi feito em Lall (1992) e, mais tarde, refinada em Bell e Pavitt (1995). Em Figueiredo (2001), esse modelo foi empiricamente adaptado para auxiliar na explicação de diferenças entre empresas de aço em termos da maneira e da taxa de acumulação de capacidade tecnológica e, por sua vez, em termos de aprimoramento de desempenho técnico-econômico (ver o modelo adaptado no Quadro 1). ${ }^{10}$

Em outras palavras, o modelo permite identificar e medir capacitação tecnológica com base em atividades que a empresa é capaz de fazer ao longo de sua existência. Com base nesse modelo, é possível distinguir entre: capacidades rotineiras, isto é, capacidades para usar ou operar certa tecnologia, e capacitaçôes inovadoras, isto é, capacidades para adaptar e/ou desenvolver novos processos de produção, sistemas organizacionais, produtos, equipamentos e projetos de engenharia, isto é, capacidades para gerar e gerir a inovação tecnológica.

Eis as razões pelas quais utiliza-se aqui essa definição ampliada de capacidade tecnológica, que é subjacente ao modelo comentado acima: seu sentido está incorporado às características da empresa que opera em uma economia emergente e, portanto, é mais adequado do que aquele adotado na literatura de empresas que operam na fronteira tecnológica internacional; seu sentido é

9 Outros modelos descrevem as trajetórias de acumulação de capacidade tecnológica adotando perspectivas diversas. $\bigcirc$ "ciclo reverso de produto" de Hobday (1995) está mais ligado à acumulação de capacidades para os mercados exportadores, ao passo que o modelo "aquisição-assimilação-aprimoramento" de Kim (1997) tem mais a ver com a acumulação de capacidade para produtos do que para outros tipos de funções tecnológicas (p. ex., equipamento, gestão de projetos, processos e organização da produção).

10 O processo de adaptação e validação desse modelo para sua aplicação empírica em um estudo centrado na indústria de aço levou aproximadamente um ano. As principais atividades desse processo envolveram a seleção das funções tecnológicas relevantes, a coleta e a classificação das atividades específicas para expressar os diversos níveis de capacidade tecnológica e uma contínua validação com diferentes profissionais de empresas de aço e especialistas da indústria. 
QUADRO 1

Capacidades tecnológicas em empresas de economias emergentes: um modelo descritivo

\begin{tabular}{|c|c|c|c|c|c|}
\hline \multirow{2}{*}{$\begin{array}{l}\text { Níveis de } \\
\text { Competências } \\
\text { Tecnológicas }\end{array}$} & \multicolumn{5}{|c|}{ Funções Tecnológicas e Atividades Relacionadas } \\
\hline & $\begin{array}{l}\text { Decisão e Controle } \\
\text { sobre a Planta }\end{array}$ & $\begin{array}{l}\text { Engenharia } \\
\text { de projetos }\end{array}$ & $\begin{array}{l}\text { Processos e } \\
\text { Organização } \\
\text { da Produção }\end{array}$ & Produtos & Equipamentos \\
\hline \multicolumn{6}{|c|}{ ROT I NA } \\
\hline (1) Básico & $\begin{array}{l}\text { Decisão sobre } \\
\text { localização da planta. } \\
\text { Termos de referência. }\end{array}$ & $\begin{array}{l}\text { Preparação inicial de } \\
\text { projeto. Sincroniza- } \\
\text { ção de trabalhos de } \\
\text { construção civil e } \\
\text { instalações. }\end{array}$ & $\begin{array}{l}\text { Coordenação de } \\
\text { rotina na planta. } \\
\text { Absorção da capaci- } \\
\text { dade da planta. PCP } \\
\text { e CQ básicos. }\end{array}$ & $\begin{array}{l}\text { Replicação de aços } \\
\text { seguindo especifica- } \\
\text { ções amplamente a- } \\
\text { ceitas. CQ de rotina. } \\
\text { Fornecimento a mer- } \\
\text { cados de exportação. }\end{array}$ & $\begin{array}{l}\text { Reposição de rotina } \\
\text { de componentes de } \\
\text { equipamento. Parti- } \\
\text { cipação em instala- } \\
\text { ções e testes de } \\
\text { performance. }\end{array}$ \\
\hline \multirow[t]{2}{*}{ (2) Renovado } & $\begin{array}{l}\text { Monitoramento ativo } \\
\text { de rotina de unidades } \\
\text { existentes na planta. }\end{array}$ & $\begin{array}{l}\text { Serviços rotineiros de } \\
\text { engenharia na planta } \\
\text { nova e/ou existente. }\end{array}$ & $\begin{array}{l}\text { Estabilidade do AF e } \\
\text { aciaria. Coordenação } \\
\text { aprimorada da planta. } \\
\text { Obtenção de certifi- } \\
\text { cação (ex. ISO 9002, } \\
\text { QS 9000) }\end{array}$ & $\begin{array}{l}\text { Replicação aprimora- } \\
\text { da de especificações } \\
\text { de aços dados ou } \\
\text { próprias. Obtenção } \\
\text { de certificação } \\
\text { internacional para } \\
\text { CQ de rotina. }\end{array}$ & $\begin{array}{l}\text { Manufatura e reposi- } \\
\text { ção de componentes } \\
\text { (ex. cilindros) sob } \\
\text { certificação interna- } \\
\text { cional (ISO 9002) }\end{array}$ \\
\hline & & \multicolumn{4}{|c|}{ INOVADORAS } \\
\hline (3) Extrabásico & $\begin{array}{l}\text { Envolvimento } \\
\text { ativo em fontes } \\
\text { de financiamento } \\
\text { de tecnologia. }\end{array}$ & $\begin{array}{l}\text { Planejamento } \\
\text { de projeto. Estudos } \\
\text { de viabilidade } \\
\text { tecnicamente } \\
\text { assistidos, para } \\
\text { grandes expansões. }\end{array}$ & $\begin{array}{l}\text { Pequenas adaptações } \\
\text { e intermitentes em } \\
\text { processos, elimina- } \\
\text { ção de gargalos, e } \\
\text { alongamento de } \\
\text { capacidade. }\end{array}$ & $\begin{array}{l}\text { Pequenas adaptações } \\
\text { em especificações } \\
\text { dadas. Criação de } \\
\text { especificações pró- } \\
\text { prias para aços (di- } \\
\text { mensão, forma, pro- } \\
\text { priedades mecânicas). }\end{array}$ & $\begin{array}{l}\text { Adaptações peque- } \\
\text { nas em equipamen- } \\
\text { tos para ajustá-los } \\
\text { a matérias primas } \\
\text { locais. Manutenção } \\
\text { break-down. }\end{array}$ \\
\hline (4) Pré-Intermediário & $\begin{array}{l}\text { Monitoramento } \\
\text { parcial e controle de: } \\
\text { estudos de viabilidade } \\
\text { de expansão, busca, } \\
\text { avaliação, e seleção } \\
\text { de tecnologia e } \\
\text { fornecedores. }\end{array}$ & $\begin{array}{l}\text { Engenharia de } \\
\text { instalações. Expan- } \\
\text { sões tecnicamente } \\
\text { assistidas. Enge- } \\
\text { nharia de deta- } \\
\text { lhamento. }\end{array}$ & $\begin{array}{l}\text { Alongamentos siste- } \\
\text { máticos de capaci- } \\
\text { dade. Manipulação } \\
\text { de parâmetros } \\
\text { chave de processo. } \\
\text { Novas técnicas } \\
\text { organizacionais } \\
\text { (TQC/M, ZD, JTT). }\end{array}$ & $\begin{array}{l}\text { Aprimoramentos siste- } \\
\text { máticos em especifi- } \\
\text { cações dadas. "Enge- } \\
\text { nharia reversa" siste- } \\
\text { mática. Desenho e } \\
\text { desenvolvimento de } \\
\text { aços tecnicamente } \\
\text { assistidos. Desenvolvi- } \\
\text { mento de especifica- } \\
\text { ções próprias. }\end{array}$ & $\begin{array}{l}\text { Reforma de grandes } \\
\text { equipamentos (ex. AF) } \\
\text { sem assistência } \\
\text { técnica. Engenharia } \\
\text { reversa de detalhe e } \\
\text { básica. Manufatura } \\
\text { de grande equipa- } \\
\text { mentos. }\end{array}$ \\
\hline (5) Intermediário & $\begin{array}{l}\text { Monitoramento } \\
\text { completo, controle e } \\
\text { execução de: estudos } \\
\text { de viabilidade, busca, } \\
\text { avaliação, e seleção, } \\
\text { e atividades de } \\
\text { financiamento. }\end{array}$ & $\begin{array}{l}\text { Engenharia básica } \\
\text { de plantas individuais. } \\
\text { Expansão da planta } \\
\text { sem assistência } \\
\text { técnica. Provisão } \\
\text { intermitente de } \\
\text { assistência técnica. }\end{array}$ & $\begin{array}{l}\text { Aprimoramento } \\
\text { contínuo de processo. } \\
\text { Desenho de sistemas } \\
\text { automatizados } \\
\text { estáticos. Integração } \\
\text { de sistemas } \\
\text { automatizados de } \\
\text { processo e PCP. } \\
\text { Alongamento rotini- } \\
\text { zado de capacidade. }\end{array}$ & $\begin{array}{l}\text { Aprimoramento contí- } \\
\text { nuo em especifica- } \\
\text { ções próprias. Dese- } \\
\text { nho, desenvolvimento, } \\
\text { manufatura e comer- } \\
\text { cialização, de aços } \\
\text { complexos e de alto } \\
\text { valor sem assistência } \\
\text { técnica. Certifica- } \\
\text { ção para desenvolvi- } \\
\text { mento de produto } \\
\text { (ex. ISO 9001). }\end{array}$ & $\begin{array}{l}\text { Continua E básica } \\
\text { e de detalhe e ma- } \\
\text { nufatura de plantas } \\
\text { individuais (ex. AF, } \\
\text { Sinter). Manuten- } \\
\text { ção preventiva. }\end{array}$ \\
\hline $\begin{array}{l}\text { (6) Intermediário } \\
\text { Superior }\end{array}$ & $\begin{array}{l}\text { Elaboração e exe- } \\
\text { cução próprias de } \\
\text { projetos. Provisão de } \\
\text { assistência técnica } \\
\text { em decisões de } \\
\text { investimentos. }\end{array}$ & $\begin{array}{l}\text { Engenharia básica } \\
\text { da planta inteira. } \\
\text { Provisão sistemática } \\
\text { de assistência técnica } \\
\text { em: estudos de } \\
\text { viabilidade, engenha- } \\
\text { ria de aquisição, de } \\
\text { detalhe, básica, e } \\
\text { partida da planta. }\end{array}$ & $\begin{array}{l}\text { Integração entre } \\
\text { sistemas operacionais } \\
\text { e sistemas corpo- } \\
\text { rativo. Engajamento } \\
\text { em processos de } \\
\text { inovação baseados } \\
\text { em pesquisa e } \\
\text { engenharia. }\end{array}$ & $\begin{array}{l}\text { Adição de valor a aços } \\
\text { desenvolvidos interna- } \\
\text { mente. Desenho e de- } \\
\text { senvolvimento de aços } \\
\text { extra complexos e de } \\
\text { alto valor agregado. } \\
\text { Engajamento em } \\
\text { projetos de desenho } \\
\text { e desenvolvimento } \\
\text { com usuários. }\end{array}$ & $\begin{array}{l}\text { Continua E básica } \\
\text { e detalhe de equipa- } \\
\text { mento para planta } \\
\text { inteira de aço e/ou } \\
\text { componentes para } \\
\text { outras indústrias. } \\
\text { Assistência técnica } \\
\text { (ex. reforma de AF) } \\
\text { para outras } \\
\text { empresas. }\end{array}$ \\
\hline
\end{tabular}

Fonte: Figueiredo (2001, 2003a,2003b). Chaves: $\mathrm{E}=$ engenharia; $\mathrm{PCP}=$ planejamento e controle da produção; $C Q=$ controle de qualidade; $\mathrm{AF}=$ alto forno. 
suficientemente amplo para atender ao objetivo de examinar o processo de acumulação tecnológica levando-se em conta tanto as dimensões técnicas quanto as organizacionais da capacidade tecnológica.

O Quadro 1 apresenta um exemplo do modelo modificado para aplicação empírica. Embora essa adaptação tenha sido feita, inicialmente, para aplicação empírica na indústria do aço, o modelo tem sido adaptado para estudos de desenvolvimento tecnológico em outros setores industriais. ${ }^{11}$ As colunas mostram as capacidades tecnológicas por função; as linhas, por nível de dificuldade. Elas são medidas pelas atividades que expressam os níveis de capacidade tecnológica ou, em outras palavras, o tipo de atividade que a empresa é capaz de realizar por si mesma em diferentes intervalos de tempo.

O modelo adaptado no Quadro 1 consiste em sete níveis de capacidade para cinco funções tecnológicas: decisão e controle sobre a planta; engenharia de projetos; processos e organização da produção; produtos; e equipamentos. As funçõos (a) e (b) são agrupadas na rubrica de "Investimentos". Com relação à aplicação empírica desse modelo é importante notar os seguintes pontos:

(a) o modelo permite captar dois tipos de trajetória de desenvolvimento tecnológico: pela evolução da simples produção de bens e serviços cada vez mais complexos e de maior valor agregado - por exemplo, da manufatura de simples aparelhos de áudio à manufatura de DVDs; pelo aprofundamento do nível de capacidade tecnológica - por exemplo, da produção básica para a engenharia, desenho e desenvolvimento de processos e/ou produtos;

(b) embora apresente a capacidade tecnológica conforme níveis ou "estágios", como em Gerschenkron (1962), o modelo não pressupõe que todas as empresas de um certo setor industrial - ou mesmo unidades de uma mesma empresa - necessariamente se capacitem nessa seqüência linear. $O$ modelo também não pressupõe que as capacidades sejam construídas, acumuladas, sustentadas (ou debilitadas), ao mesmo tempo e à mesma velocidade, para

\footnotetext{
11 Ver, p. ex., Ariffin (2000) e Ariffin \& Figueiredo (2003) para a indústria eletrônica; Tacla \& Figueiredo (2003) para indústria de bens de capital fornecedora de sistemas de produção para a indústria de celulose e papel. Uma adaptação para a indústria de motocicletas e bicicletas foi realizada em Vedovello \& Figueiredo (2003). No âmbito do Programa de Pesquisa em Aprendizagem Tecnológica e Inovação Industrial no Brasil, da EBAPE/FGV, adaptações têm sido feitas em estudos empíricos de desenvolvimento tecnológico em empresas de diferentes setores industriais no Brasil: metalmecânico, linha branca (geladeiras, máquinas de lavar, ar-condicionado e fornos microondas), componentes eletrônicos, telefonia celular e fixa.
} 
as diferentes funções tecnológicas. Ademais, é difícil fazer uma separação entre as atividades relacionadas aos produtos e o processo de sua fabricação, incluindo-se aí o instrumental e o equipamento utilizado;

(c) em estudos em nível de empresas - e mesmo de setores industriais - recomenda-se classificar as funções tecnológicas específicas (p. ex., produtos, processo e organização da produção), em termos de tipos e níveis de capacidades, em vez da empresa ou do setor industrial em si (ver, p. ex., Dutrénit, 2000; Figueiredo, 2003a, 2003b). Empresas acumulam suas capacidades para funções tecnológicas diversas em diferentes maneiras, direções e a diferentes velocidades. Para certa função tecnológica (p. ex., produtos) pode-se alcançar uma profundidade de capacidade tecnológica (p. ex., nível 5), enquanto que em uma outra função (p. ex., gestão de projetos) pode-se acumular um nível mais superficial (p. ex., nível 2);

(d) ademais, e lembrando que a acumulação de capacidades rotineiras e inovadoras ocorre de maneira paralela dentro da empresa - e do setor industrial -, é possível uma empresa acumular partes de certas capacidades inovadoras sem que a acumulação de suas capacidades rotineiras esteja consolidada. Chamamos a isso de acumulação truncada ou incompleta, fenômeno observado, com certa freqüência, em empresas que operam em economias ou áreas emergentes (ver Dutrénit, 2000; Ariffin, 2000; Figueiredo, 2001, 2003a).

A aplicação empírica mais sofisticada desse modelo permite ainda examinar a velocidade (ou taxa) de acumulação, isto é, o número de anos que uma empresa leva para alcançar certo nível de capacidade para funções tecnológicas específicas. Também é possível identificar quanto tempo certa empresa - ou conjunto de empresas - permaneceu estacionada em certo nível de capacidade tecnológica. Exemplos de medições de velocidade de acumulação de capacidade tecnológica aparecem em Figueiredo (2001, 2002, 2003a), enquanto que um método e sua aplicação empírica sistemática na indústria eletroeletrônica são desenvolvidos em Ariffin (2000). Essa preocupação em medir o tempo de acumulação tecnológica, presente nesses dois estudos - embora crucial para empresas de economias emergentes, como mencionado na Seção 2, ainda é uma questão negligenciada em estudos empíricos e em estratégias de inovação industrial. 
FIGURA 2

Trajetória de acumulação de capacidade tecnológica em empresas de economias emergentes: um modelo ilustrativo

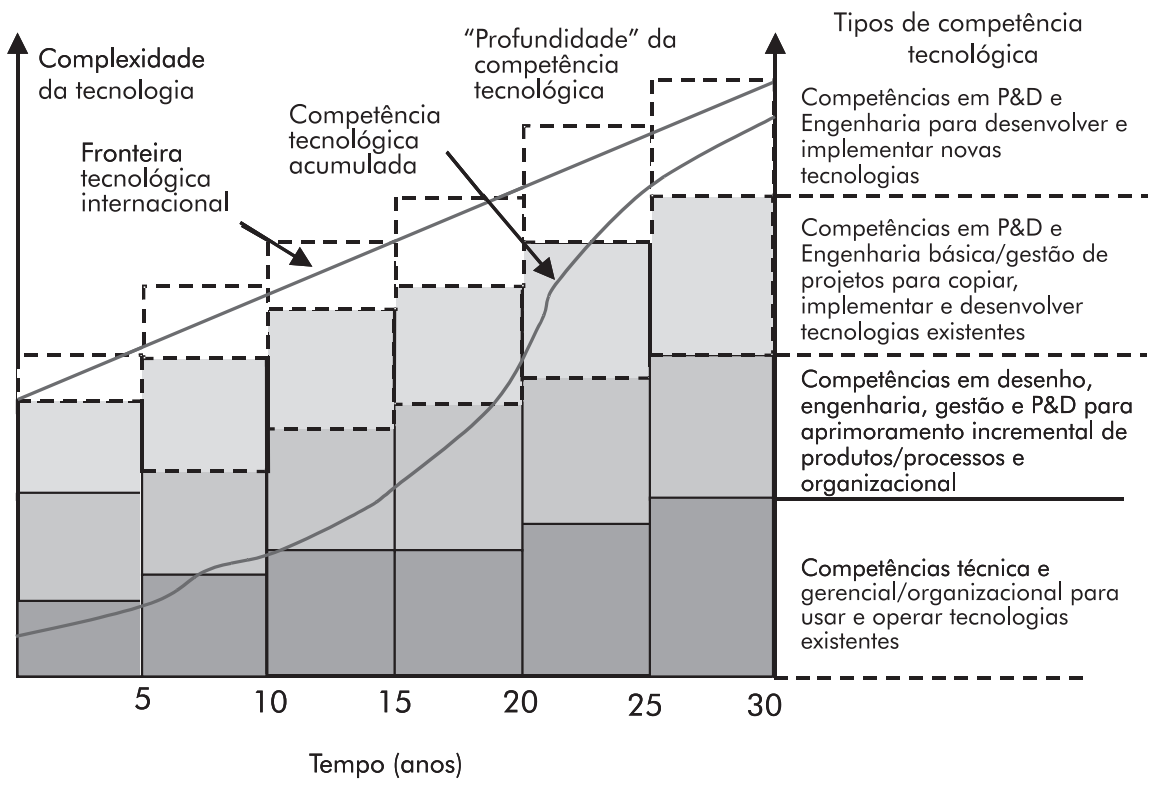

Fonte: Bell (1997). Ver aplicação empírica em Figueiredo (2001, 2003b)

Como uma extensão do modelo no Quadro 1, a Figura 2 (a "escada") é uma estrutura auxiliar, que facilita a visualização da trajetória tecnológica de empresas de economias emergentes. No eixo vertical direito encontram-se as capacidades tecnológicas classificadas por níveis. No nível mais elevado estão as atividades tecnológicas fortemente baseadas em pesquisa, projeto e desenvolvimento. Tão importante quanto mirar a acumulação desse nível mais avançado de capacidade tecnológica, é entender que a construção e a acumulação de capacidade tecnológica em níveis intermediários são uma precondição para o alcance dos níveis mais avançados (Dosi, 1988a; Lall, 1992; Hobday, 1995; Bell \& Pavitt, 1993, 1995; Dutrénit, 2000; Ariffin, 2000; Figueiredo, 2001, 2003a). Entretanto, estudos sobre inovação industrial em economias emergentes tendem a ignorar a importância da acumulação das capacidades em níveis intermediários e como e quanto tempo empresas evoluem da acumulação de capacidades rotineiras para capacidades inovadoras - de básicas a avançadas. 
FIGURA 3

Atividades tecnológicas na empresa eletrônica global

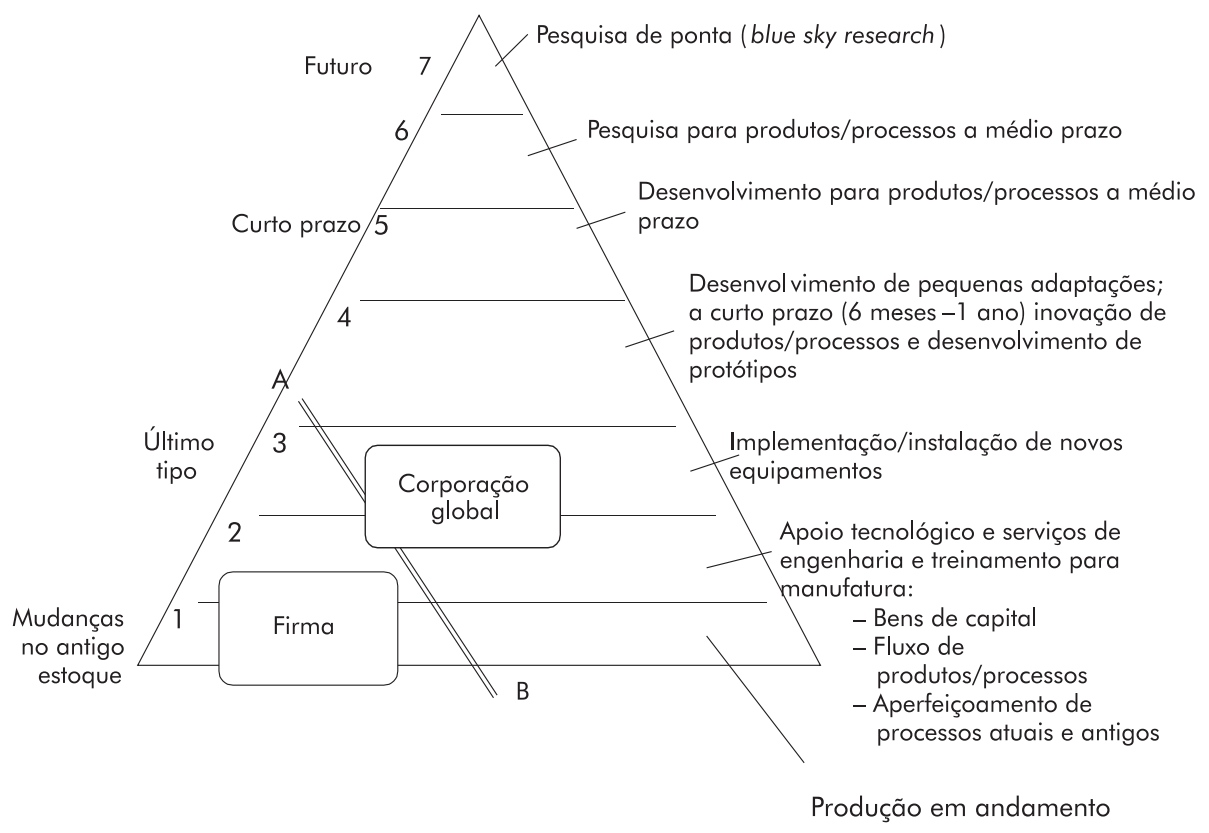

Fonte: Hobday (1999). "Understanding innovation in electronics in Malaysia", In Industrial Technology Development in Malaysia: Industry and Firm Studies, eds. Jomo K.S, G. Felker \& Rajah Rasiah, Routledge, UK, p.97.

Por isso, a aplicação empírica dos modelos no Quadro 1 e da Figura 2 permite levantar questões aparentemente simples, mas, cuja busca sistemática e disciplinada de respostas, pode conduzir a uma estratégia de inovação industrial focada e coerente - tanto em nível de empresas como de setor industrial ou mesmo de um país: onde estamos (empresa ou setor industrial) em termos de capacidade tecnológica? quanto tempo levamos para chegar até aqui? por quanto tempo estamos "estacionados" em certo nível de capacidade para uma função tecnológica específica? quão distante estamos da fronteira tecnológica internacional? onde queremos estar até o ano $X$ ? quais são os recursos e como gerilos para se alcançar certo nível de capacidade tecnológica em $X$ número de anos?

Outro modelo auxiliar cuja lógica é similar àquela do Quadro 1 e a da Figura 2, é o modelo classificatório de Hobday (1999) - ver Figura 3. Tal métrica é, porém, específica para o exame de desenvolvimento tecnológico na indústria eletrônica em economias emergentes. Trata-se de uma indústria fortemente inter- 
nacionalizada que opera à base de empresas transnacionais e suas subsidiárias ao redor do mundo. Por isso, esse modelo é particularmente útil para auxiliar na aferição do grau de capacidade tecnológica em subsidiárias de empresas estrangeiras que operam no Brasil (ver, p. ex., Ariffin \& Figueiredo, 2003).

O modelo da Figura 3 mostra os níveis de atividade tecnológica, desde (1) mudanças no antigo estoque por meio de apoio tecnológico e serviços de engenharia; (2) capacidade para instalar equipamento de último tipo; (3) adaptaçôes e desenvolvimento de produtos e processos a curto prazo; (4) desenvolvimento e pesquisa a médio prazo; até (5-7) pesquisa de ponta. Tal classificação oferece uma perspectiva geral das atividades de (5) a (7) que podem ser classificadas como "P\&D", ou seja, equivalentes aos níveis 6 e 7 do Quadro 1.

No entanto, estudos sobre o desenvolvimento tecnológico em economias emergentes, incluindo o Brasil, que lançam mão das estatísticas sobre patentes e dos gastos com P\&D, como indicadores da atividade tecnológica, tendem a buscar, de um lado, apenas evidências sobre as atividades avançadas do "topo da pirâmide" - níveis de 5 a 7 da Figura 3 - ou limitam-se a identificar a incidência, ou não, de atividades inovadoras. Ignoram-se, portanto, os diversos níveis intermediários de capacidade tecnológica - que são predominantes em empresas em economias emergentes e, de cujo processo de aprofundamento cumulativo, depende o alcance de níveis tecnológicos mais sofisticados (Hollander, 1965; Dosi, 1988a, 1988b; Dahlman et al., 1987; Lall, 1992; Bell \& Pavitt, 1995; Bell, 1996; Kim, 1997; Bessant, 1998; Dutrénit, 2000; Ariffin \& Bell, 1999; Ariffin, 2000; Figueiredo, 2001, 2003a).

Ou seja, busca-se a existência, ou não, de atividades tecnológicas inovadoras sem, contudo, captar os níveis de capacidades e seu modo e velocidade de acumulação. Como conseqüência, gera-se uma perspectiva linear e polarizada de inovação e de capacidade tecnológica, que considera dois extremos: básica (simples montagem - sem atividades inovadoras) ou avançada (baseada em patentes e P\&D).

De um lado, estudos empíricos conduzidos à base dessa perspectiva limitada e polarizada de inovação e de capacidade tecnológica podem conduzir a interpretações enganosas da realidade industrial e, por conseguinte, gerar recomendações equivocadas de política governamental. De outro, esse tipo de perspectiva contribui para facilitar a disseminação de certas generalizações co- 
muns sobre o desenvolvimento tecnológico de setores industriais ou mesmo de países. Pode-se mencionar aqui exemplos de regióes industriais que, ao longo dos anos, têm sido vistas à luz desses tipos de generalizações comuns: Klang Valley e Penang (Malásia) e Manaus (Amazonas).

Com relação à indústria eletrônica nessas regiōes, dissemina-se a noção de que as empresas locais e subsidiárias de empresas transnacionais que lá operam têm feito muito pouco (ou quase nada) em termos de desenvolvimento de capacidades tecnológicas. Mais especificamente, generaliza-se a idéia de que as empresas são apenas "maquiladoras" que realizam simples montagem, na maioria dos casos, para obterem benefícios fiscais e que suas atividades tecnológicas estão confinadas aos níveis mais básicos de "produção" ou de "tecnologia de processo". Tais generalizações refletem não apenas uma perspectiva limitada de capacidade tecnológica e de inovação, mas a ausência de estudos empíricos criteriosos, dos anos 1970 ao final dos anos 1990, sobre o desenvolvimento tecnológico em empresas nessas áreas. Isso motivou a emergência de estudos empíricos, com adequado nível de profundidade e detalhe, à luz de métricas adequadas tanto na Malásia como no Brasil (ver Ariffin \& Bell, 1999 e Ariffin, 2000 - para o contexto da Malásia, e Ariffin $\&$ Figueiredo, 2003 - para caso do Brasil). ${ }^{12}$

Contrariando as generalizações comuns e negativas, as evidências e análises desses estudos revelaram uma realidade industrial dinâmica, inovadora e internacionalmente competitiva em termos tecnológicos. Ao contrário do que pode ser argumentado, o foco de análise em Ariffin e Bell (1999), Ariffin (2000) e Ariffin e Figueiredo (2003), não se limita meramente ao "chão de fábrica" das empresas pesquisadas. Uma vez que tais estudos foram desenhados e implementados à luz da definição abrangente de capacidade tecnológica (como explicitado na Seção 2), foram examinadas as diversas unidades organizacionais envolvidas com atividades tecnológicas nas amostras das empresas pesquisadas, no âmbito das áreas/regiôes onde operam. Logo, enfoques limitados, que resultam no autoflagelo, podem e devem dar lugar a abordagens mais sofisticadas que resultem em estratégias governamentais e empresariais positivas, promotoras do desenvolvimento tecnológico.

\footnotetext{
12 Uma análise comparativa entre Klang Valley, Penang e Manaus, em termos de desenvolvimento tecnológico em uma amostra de 82 empresas, foi desenvolvida em Ariffin \& Figueiredo (2004).
} 


\subsection{Vínculos entre empresas e a infra-estrutura de tecnologia e inovação}

Embora o desenvolvimento de capacidade tecnológica industrial ocorra primariamente dentro de empresas (Bell \& Pavitt, 1995), a infra-estrutura tecnológica e de inovação (universidades e seus diversos departamentos, institutos públicos e privados de pesquisa, centros de formação e treinamento, consultorias, banco de dados) podem contribuir para o processo inovador em nível de empresas. Por isso, é ponto comum em documentos de política tecnológica no Brasil a recomendação de fortalecimento dos vínculos entre empresas e a infra-estrutura de tecnologia e inovação, ou seja, um maior ajuste entre os vários atores que compõem o sistema local e/ou nacional de inovação.

Mais especificamente, infra-estrutura tecnológica é aqui definida como um conjunto de arranjos institucionais organizados com o objetivo básico de facilitar a disseminação de tecnologia e outros conhecimentos relacionados, de fontes relevantes para as empresas e outras organizaçôes, para auxiliá-las no desenvolvimento de suas capacidades tecnológicas e na adoção, produção e comercialização de inovações. Estes arranjos institucionais cobrem uma diversidade de mecanismos e processos que servem de apoio para a provisão de serviços, tais como contratos de pesquisa, assistência técnica, certificação, consultoria, treinamento. Em geral, tais arranjos são criados e/ou mantidos através da provisão de recursos (financeiros) públicos que permitem que a oferta de serviços acima mencionada ocorra a um preço abaixo do de mercado (Vedovello \& Godinho, 2003). Essa perspectiva sobre a infra-estrutura tecnológica transcende a abordagem convencional de infra-estrutura física - baseada somente no capital físico e humano, mas envolve também elementos institucionais e organizacionais que apóiam as atividades inovadoras das empresas.

Adicionalmente, ao longo dos últimos anos, vários mecanismos de apoio financeiro têm sido implementados para a formação e consolidação de infraestruturas de tecnologia e inovação no Brasil. Porém, muito pouco tem sido feito em termos de avaliação das reais implicações da construção e do funcionamento de tais infra-estruturas para o desenvolvimento de capacidade tecnológica em empresas no Brasil. Neste sentido, a métrica desenvolvida em Vedovello $(1995,2001)$ contém elementos que permitem examinar a natureza 
das interações que podem ser estabelecidas entre a indústria e a infra-estrutura tecnológica. Essa métrica considera se as interações são baseadas, ou não, no estabelecimento de contatos formais entre os parceiros, no compromisso dos vários atores envolvidos, assim como no pagamento, ou não, de taxas para que as mesmas se efetivem. As interações que emergem destas considerações são agrupadas em três diferentes conjuntos: ligações informais, ligações vinculadas à formação e aperfeiçoamento de recursos humanos e ligações formais, descritas nos Quadros 2 e 3.

\section{QUADRO 2}

Tipos de ligação entre a infra-estrutura tecnológica e a indústria

Ligações informais

Recursos humanos

Ligações formais
1. Contatos informais com pesquisadores

2. Acesso à literatura especializada

3. Acesso à pesquisa de departamentos específicos

4. Participação em seminários e conferências

5. Acesso aos equipamentos da universidade e/ou dos institutos de pesquisa

6. Participação em programas específicos (educacionais e de treinamento)

7. Outras ligações informais

8. Envolvimento de estudantes em projetos industriais

9. Recrutamento de recém-graduados

10. Recrutamento de cientistas e engenheiros mais experientes

11. Programas de treinamento formalmente organizados para atender às necessidades dos recursos humanos

12. Outras ligações relacionadas aos recursos humanos

13. Consultoria desenvolvida por pesquisadores ou consultores

14. Análises e testes (ensaios técnicos)

15. Serviços de atualização de acervo (normas técnicas atualizadas, patentes)

16. Respostas técnicas (diagnóstico de problemas em termos de processo produtivo)

17. Estabelecimento de contratos de pesquisa

18. Estabelecimento de pesquisa conjunta

19. Outras ligações formais 
QUADRO 3

Níveis de classificação das ligações entre a infra-estrutura tecnológica e a indústria

Em termos de freqüência

Em termos de resultados obtidos

Em termos de benefícios alcançados

$$
\begin{aligned}
& 0=\text { até } 2 \text { vezes ao ano } \\
& 1=\text { de } 3 \text { a } 6 \text { vezes ao ano } \\
& 2=\text { uma vez ao mês } \\
& 3=\text { uma vez por semana ou mais }
\end{aligned}
$$

$A=$ conselhos verbais

$B=$ fornecimento de informações

$\mathrm{C}=$ relatórios

$D=$ implementação de programas específicos

$\mathrm{E}=$ especificações de design

$\mathrm{F}=$ protótipos

$G=$ patentes

$\mathrm{H}=$ outros (especificar)

$0=$ nenhum benefício

$1=$ pequeno benefício

2 = benefício moderado (complementar)

3 = grande benefício (crucial)

Fonte: Vedovello $(1995,2001)$

Portanto, o modelo desenvolvido em Vedovello (1995) permite captar as nuanças das interações entre os diferentes atores do sistema nacional/local de inovação. A sua aplicação empírica pode orientar o processo de desenho de estratégias mais adequadas à realidade e às necessidades dos próprios sistemas. ${ }^{13}$

\subsection{Processos de aprendizagem tecnológica}

Lembrado que a maneira e a velocidade de acumulação de capacidades tecnológicas estão fortemente associadas à gestão dos vários processos de aprendizagem nas empresas ao longo do tempo (Figueiredo, 2001, 2003b), é apresentada nesta seção a métrica que permite examinar as implicações práticas dos processos de aprendizagem para a acumulação de capacidade tecnológica (rotineira e inovadora) em empresas e setores industriais.

O modelo, desenvolvido em Figueiredo (2001, 2003a), identifica os vários

\footnotetext{
${ }^{13}$ A aplicação dessa métrica para examinar as implicações da infra-estrutura de tecnologia e inovação para o desenvolvimento de diferentes tipos e níveis de capacidades tecnológica, em nível de empresas, das indústrias de eletrônica de consumo, motocicletas e bicicletas e seus principais fornecedores foi realizada em Vedovello \& Figueiredo (2003).
} 
processos por meio dos quais a empresa adquire conhecimentos técnicos - via fontes externas e internas - para a construção de sua capacidade tecnológica. $\mathrm{O}$ modelo consiste em quatro processos de aprendizagem (linhas do Quadro 4), cada qual incluindo diferentes mecanismos. Esses processos são examinados à luz de quatro características: variedade, intensidade, funcionamento e interação (colunas do Quadro 4). ${ }^{14}$

A aplicação desse modelo contribui para gerar, com adequado grau de profundidade e de detalhe, explicaçôes sobre a maneira e a velocidade do processo de acumulação de capacidade tecnológica que podem orientar estratégias empresariais e também governamentais de inovação.

\subsection{Vínculos tecnológicos interempresariais}

Um dos objetivos de estratégias de inovação industrial é o fortalecimento da capacidade tecnológica de empresas locais de pequeno e médio porte no intuito de exercerem um papel mais competitivo na cadeia de fornecedores de grandes empresas locais e também de empresas transnacionais.

Por isso, é apresentado aqui o modelo que permite examinar os vínculos tecnológicos interempresariais desenvolvido em Ariffin (2000). Esse modelo permite compreender os vínculos de saber e aprendizagem tecnológica existentes entre as empresas, em especial no contexto de economias emergentes (ver Quadro 5). Tal método envolve a combinação de duas importantes distinções. Primeiramente, a distinção entre:

(1) os vínculos relativos às transações de mercado em bens e serviços; e

(2) os vínculos relativos aos fluxos de saber.

Em segundo lugar, a distinção entre:

(3) os vínculos baseados principalmente no uso da capacidade já existente nas empresas; e

(4) os vínculos que contribuem significativamente para gerar essa capacidade.

14 Definições detalhadas e critérios, assim como a aplicação empírica desse modelo em empresas de aço, bens de capital, de produtos de linha branca e metal-mecânica podem ser encontrados, respectivamente em Figueiredo (2001, 2003a), Tacla \& Figueiredo (2003), Ferigotti \& Figueiredo (2003). 
QUADRO 4

Processos de aprendizagem: modelo de análise

\begin{tabular}{lcccc}
\hline $\begin{array}{c}\text { Processos de } \\
\text { Aprendizagem }\end{array}$ & \multicolumn{3}{c}{ Características-chave dos processos de aprendizagem } \\
& $\begin{array}{c}\text { Variedade } \\
\text { Ausente-Presente }\end{array}$ & Intensidade & Funcionamento & Interação \\
& Una vez-Intermitente- & Ruim - Moderado - & Fraca - Moderada - \\
& $\begin{array}{c}\text { Cimitada - Moderada } \\
\text { Diversa }]\end{array}$ & Contínuo & Bom - Excelente & Forte
\end{tabular}

Processos e Mecanismos de Aquisição de Conhecimento

$\begin{array}{ll}\text { Aquisição } & \text { Presença/ausência } \\ \text { Externa de } & \text { de processos para } \\ \text { Conhecimento } & \begin{array}{l}\text { adquirir conhecimento } \\ \text { localmente e/ou no } \\ \text { exterior. }\end{array}\end{array}$

Interna de

Conhecimento

\begin{abstract}
Presença/ausência de processos para adquirir conhecimento fazendo atividades internas (ex. experimentação). Essas podem ser atividades de rotina ou inovadoras.

modo como a empresa usa diferentes processos para aquisição interna de conhecimento. Isso pode influenciar o entendimento pelos indivíduos dos princípios envolvidos na tecnologia.
\end{abstract}

\author{
modo como a \\ empresa usa este \\ processo ao longo \\ do tempo pode ser \\ contínuo (ex. treina- \\ mento anual no \\ exterior para enge- \\ nheiros e operadores), \\ intermitente, ocorrer \\ apenas uma vez.
}

\author{
modo como o \\ processo é criado \\ (ex. critério para enviar \\ engenheiros para \\ treinamento no exterior) \\ e o modo como ele \\ opera ao longo do \\ tempo podem fortalecer \\ ou mitigar variedade e \\ intensidade. Tempo: \\ "aprender-antes-de- \\ fazer"
}

modo como o processo é criado (ex. centros de pesquisa), e o modo como ele opera ao longo do tempo tem implicações práticas para variedade e intensidade. Tempo: "aprenderantes-de-fazer" modo como um processo influencia outro processo de aquisição externa ou interna de conhecimento (ex. treinamento no exterior, "aprender fazendo") e/ou outros processos de conversão de conhecimento.

Processo de conhecimento interno pode ser influenciado por processo de aquisição externa (ex. aprimoramentos na planta influenciado por treinamento no exterior). Isso pode influenciar processos de conversão de conhecimento.

\section{Processos e Mecanismos de Conversão de Conhecimento}

\section{Socialização de conhecimento}

\section{Codificação de conhecimento}

Presença/ausência de diferentes processos através dos quais indivíduos compartilham seu conhecimento tácito (ex. encontros, solução compartilhada de problemas).

Presença/ausência de diferentes processos e mecanismos para codificar o conhecimento tácito (ex. documentação sistemática, seminários internos). modo como processos (ex. treinamento no trabalho) prosseguem dos ao longo dos anos Intensidade contínua do processo de socialização do conhecimento pode influenciar codificação do conhecimento.

modo como processos como padroniza- $O$ modo como a ção de operações são repetidamente feitos. Codificação ausente e/ou intermitente pode limitar a aprendizagem organizacional.
O modo como mecanismos de socialização do conhecimento são criados (ex. treinamento interno) e operam ao longo do tempo. Isso tem implicações para a variedade e intensidade do processo de conversão de conhecimento.

codificação de conhecimento é criada e opera ao longo do tempo tem implicações para o funcionamento de todo o processo de conversão de conhecimento. Isso também influencia variedade e intensidade do processo.
Condução de diferentes conhecimentos tácitos para um sistema efetivo (ex. criação de links de conhecimento). Socialização pode ser influenciada por processos de aquisição externa e interna de conhecimento.

O modo como codificação de conhecimento é influenciada por processos de aquisição de conhecimento (ex. treinamento no exterior) ou por processos de compartilhamento de conhecimento (ex. construção de equipes).

Fonte: Figueiredo (2001, 2003a, 2003b) 
Vínculos (1) e (3) podem existir quando as transações de mercado em bens e serviços envolvem pouca ou nenhuma transferência de aptidões e conhecimentos que ampliem a capacidade tecnológica já existente nas empresas. Por outro lado, os vínculos entre empresas - (2) e (4) - podem envolver considerável fluxo de aptidões e conhecimentos que ajudem as empresas a desenvolver sua capacidade, seja em termos de produção (como em vários contratos de licenciamento), seja de capacidade para realizar atividades tecnológicas inovadoras.

Esse modelo é particularmente útil para examinar vínculos entre empresas em um certo setor industrial (e cadeia de fornecedores), independentemente do seu tamanho e da sua nacionalidade. A sua aplicação empírica permite captar não apenas a existência, ou não, de vínculos entre empresas, mas, principalmente, $o$ que vai dentro de cada vínculo, em termos de fluxo de conhecimento tecnológico. Ou seja, pode-se examinar se os vínculos relacionam-se ao uso de capacidades tecnológicas existentes ou ao desenvolvimento de capacidades para realizar atividades tecnológicas inovadoras. Isso é particularmente importante para aferir o desenvolvimento tecnológico em pequenas e médias empresas.

A despeito da fabulosa retórica sobre a importância das pequenas e médias empresas para a geração de empregos e de inovação, as medidas governamentais tendem a considerá-las de maneira isolada (no que se refere, p. ex., a microcrédito, apoio a treinamentos gerenciais, avaliação de potencialidade para realização de projetos, etc.), sem examinar adequadamente seu processo de desenvolvimento tecnológico por meio dos vínculos e interações que desenvolvem em seus setores específicos - e seu posicionamento nas cadeias de fornecedores - em que operam.

$\mathrm{Na}$ verdade, tais medidas tendem a ignorar que, diferentemente das grandes empresas, as pequenas empresas inovadoras - quando conseguem levar a frente suas atividades tecnológicas - são especializadas em suas estratégias, concentrando-se em inovação de produtos específicos como máquinas-ferramenta, instrumentos científicos, produtos químicos especializados e software. Sua força estratégica-chave é combinar capacidade tecnológica com requisitos específicos de clientes (Pavitt, 1991). No contexto de economias emergentes, porém, essa habilidade de desenvolver capacidades-nicho é particularmente mais arriscada, apresentando grandes ocorrências de fracasso.

Por isso, estudos empíricos de desenvolvimento tecnológico, em vez de tomar as pequenas empresas de maneira isolada, deveriam examinar o seu re- 
lacionamento com as demais empresas envolvidas nas diversas camadas de fornecedores, para identificar como empresas médias e pequenas locais poderiam beneficiar-se dos vínculos interorganizacionais para consolidaram-se como fornecedores qualificados de médias e grandes empresas locais e transnacionais. Por isso, esses vínculos podem ser examinados entre três grupos de empresas:

(a) grupo 1 -subsidiárias estrangeiras de primeira camada que produzem uma variedade de produtos para os mercados interno e externo; são produtoras diretas de produtos e componentes, e não apenas fornecedores de subsistemas e contratos de manufatura de serviços para outras subsidiárias.

(b) grupo 2 - empresas que são fornecedores locais e dependentes de vendas para empresas do grupo 1.

(c) grupo 3 - empresas locais "independentes", que vendem seus produtos e serviços para um mercado mais geral, tanto interno como exportador, e são bastante independentes de firmas do grupo 1 .

Essa tipologia de vínculos tecnológicos interempresariais fornece um modelo geral para examinar os fluxos de conhecimento entre empresas de diferentes setores industriais. Estudos empíricos baseados na aplicação empírica desse modelo são encontrados em Ariffin e Bell (1999), Ariffin (2000) e Ariffin e Figueiredo (2003).

\section{Comentários finais e recomendações}

Este artigo procurou contribuir para o aprimoramento do desenho e da implementação de estudos empíricos e de estratégias de inovação industrial no Brasil por meio da apresentação de definiçôes e métricas. Tal iniciativa pode ser interpretada por alguns como "por demais acadêmica". Contudo, convém reiterar que tem havido uso indiscriminado de certos termos relativos à inovação industrial - sem adequada fundamentação analítica e empírica. Essa prática pode deturpar e interferir negativamente no processo de desenho e implementação de estratégias governamentais e empresariais de inovação. Por isso, foram apresentadas aqui definições e métricas (ou taxonomias) fundamentadas em suas bases conceituais e exemplificadas algumas de suas aplicações empíricas. Elas 
são importantes, particularmente para o contexto da indústria no Brasil, pelos motivos expostos a seguir.

1. Permitem esclarecer as definições subjacentes ao desenho de estudos empíricos e de estratégias de inovação industrial. A partir de uma noção mais clara do real escopo do tema e das variáveis envolvidas, é possível calibrar, desenhar ou redesenhar estratégias com foco mais coerente com as necessidades do contexto industrial e tecnológico do Brasil e das suas diferentes regiōes.

2. Permitem auxiliar a condução de novos estudos de inovação industrial, baseados fortemente em trabalho de campo - em vez de basear-se somente em análise de estatísticas oficiais - a fim de coletar evidências, tanto qualitativas como quantitativas, de primeira mão, no intuito de captar, com adequado nível de detalhe e profundidade, a realidade das atividades tecnológicas na indústria. Isso contribuiria para ampliar o debate além das generalizações comuns - ou mesmo derrotistas - sobre o desenvolvimento tecnológico na indústria que, de tempos em tempos, emergem não apenas no Brasil, mas também na América Latina. Mais especificamente, a aplicação empírica das métricas aqui apresentadas permite:

(a) avaliar, identificar e qualificar, de modo contínuo e à luz de taxonomias coerentes, o nível tecnológico dos setores industriais-chave da economia brasileira;

(b) identificar a maneira e a velocidade com que certos setores têm acumulado suas capacidades tecnológicas ao longo do tempo;

(c) ou seja, distinguir os setores mais dinâmicos dos mais lentos em termos de acumulação de capacidades tecnológicas. Por exemplo, setores mais vagarosos em termos de acumulação tecnológica talvez necessitem de incentivos diferentes e de maior exposição às pressões competitivas internacionais;

(d) identificar setores industriais que têm maior potencial para receber mais atenção - em termos de recursos materiais, humanos, técnicos, organizacionais e financeiros - para aprofundar o desenvolvimento de capacidades tecnológicas;

(e) recomendar políticas específicas para disseminar atividades que conduzam 
ao desenvolvimento de capacidades tecnológicas nos setores mais relevantes para cada uma das regiōes do Brasil.

Por isso, no intuito de contribuir para facilitar a materialização de certos objetivos, tanto governamentais como empresariais, como por exemplo, o alcance de alto nível de desempenho inovador e exportador numa perspectiva de 2020 para certos segmentos da indústria no Brasil, sugere-se a criação de metas de desenvolvimento de capacidade tecnológica. Isso significa criar prazos para o alcance de diferentes tipos e níveis de capacidades tecnológicas para os diferentes setores industriais no longo prazo, com avaliação a cada dois anos. Essa medida possibilitaria que ajustes periódicos em termos, por exemplo, de fortalecimento e/ou reorganização da infra-estrutura tecnológica e de processos de aprendizagem pudessem ser implementados, a fim de contribuir para a materialização dos níveis tecnológicos desejados. O processo de elaboração e implementação das metas de desenvolvimento de capacidade tecnológica poderia envolver lideranças empresariais, governamentais, da academia, e de outras organizações da sociedade comprometidas com o desenvolvimento industrial e tecnológico nacional.

Estudos industriais baseados em medições de desenvolvimento tecnológico, à luz de modelos coerentes, têm sido implementados, com estímulo governamental, em países industrializados. Essas práticas também são implementadas em países emergentes. Por exemplo, a Malásia, que fixou a meta de tornar-se um país tecnologicamente desenvolvido até 2020, formou recentemente um grupo de trabalho, internacional e interinstitucional, justamente para examinar tipos, níveis e velocidade de acumulação de capacidades tecnológicas em setores industriais estratégicos para a sua economia: de óleo de palma a semicondutores. Isso também mostra que a responsabilidade pelo aprimoramento da estratégia de inovação industrial de um país não é apenas do governo federal, mas também envolve o setor privado e outros componentes do sistema nacional de inovação.

Como sugere a perspectiva subjacente ao modelo na Figura 2 (a "escada”), durante o processo de desenho de estratégias de inovação industrial é importante distinguir dois tipos de desenvolvimento de capacidade tecnológica: rotineira (para usar) e inovadora (para gerar e gerir mudança 
tecnológica). Enquanto governos estão interessados em acelerar ambos os tipos de trajetória, diferentes recursos e ações são necessários para cada caso. Decisões relativas a essas duas trajetórias estão no coração das opções estratégicas de desenvolvimento industrial de um país.

Para economias emergentes, a questão-chave é não apenas calibrar o grau de incentivos a empresas, como por exemplo, para compra de máquinas e equipamentos ou exportação (abordagem estática), mas, em paralelo, estimular que um grande número de empresas se mova, com adequada velocidade, para a acumulação de níveis inovadores de capacidade tecnológica por meio de um contínuo processo de aprendizagem (abordagem dinâmica).

Finalmente, o tipo de desenvolvimento industrial seguido por empresas e países deriva, em grande parte, da qualidade das decisões estratégicas tomadas em certo ponto no tempo. Por isso, as opções feitas hoje sobre a diretriz de desenvolvimento industrial e tecnológico no Brasil certamente influenciarão o nível - e a velocidade - de nosso desenvolvimento econômico (e social) nas próximas décadas.

De fato, atingir níveis de inovação próximos daqueles alcançados por empresas de países hoje tecnologicamente avançados não é tarefa fácil. Porém, perspectivas que advogam o desenvolvimento industrial de economias emergentes, por exemplo, à base de proteção tarifária e subsídios - no intuito de resgatar a experiência histórica de certos países hoje tecnologicamente avançados (p. ex., Chang, 2002), parecem duvidosas. Evidências e análises de estudos sobre inovação industrial, realizados ao longo das últimas décadas alguns citados aqui - sugerem que a gestão dos vários processos de aprendizagem tecnológica, em nível de empresas, associada a diferentes estratégias governamentais, que convergem para apoiar e estimular o desenvolvimento tecnológico na indústria, são fatores essenciais para que empresas de economias emergentes sigam uma trajetória ascendente na intricada "escada" de capacidades tecnológicas. 


\section{Referências bibliográficas}

Alário-Junior, D.; Oliveira, N. B. de, "A inovação tecnológica e a indústria nacional”, in Parcerias Estratégicas, n.8, p.45-53, 2000.

Amann, E.; Baer, W., "From Technology Absorption to Technology Production: industrial strategy and technological capacity in Brazil's development process", in Economia Aplicada, v.3, n.1, p.109-138, 1999.

Andreassi, T.; Sbragia, R., "Fatores Determinantes do Grau de Novatividade das Empresas: um Estudo Utilizando a Técnica de Análise Discriminante”, in Série de working papers da FEA-USP, n.001/004, www.ead.fea.usp.br/wpapers, 2002.

Ariffin, N., The Internationalisation of Innovative Capabilities: the Malaysian Electronics Industry. Thesis (D. Phil.), SPRU, Brighton: University of Sussex, 2000.

; Bell, M., "Firms, Politics and Political Economy: patterns of subsidiary-parent linkages and technological capability-building in electronics TNC subsidiaries in Malaysia”, in Jomo, K. S.; Rasiah, R.; Felker, G. (orgs.), Industrial Technology Development in Malaysia, Londres: Routledge, 1999.

; Figueiredo, P. N., Internacionalização de Capacidades Tecnológicas: Implicaçôes para Estratégias Governamentais e Empresariais de Inovação e Competitividade da Indústria Eletrônica no Brasil, Rio de Janeiro: FGV, 2003.

; ___ Internationalisation of innovative capabilities: counter-evidence from the electronics industry in Malaysia and Brazil, Oxford development Studies, (no prelo), 2004.

Bell, M., Technical Change in Infant Industries: a Review of the Empirical Evidence. Brighton: SPRU, University of Sussex, 1982.

, "Technology Transfer to Transition Countries: are there Lessons from the Experience of the Post-War Industrialising Countries?", in Dyker, D. (org.), The Technology of Transition: Science and Technology Policies for Transition Countries, Central European University Press, p.63-94, 1996.

; Pavitt, K., "Technological Accumulation and Industrial Growth: Contrast Between Developed and Developing Countries", in Industrial and Corporate Change, v.2, n.2, p.157210, 1993.

; ___ “The Development of Technological Capabilities”, in Ul Haque, I.; Bell, M.; Dahlman, C; Lall, S.; Pavitt, K., Trade, Technology and International Competitiveness, Washington, DC: The World Bank, p.69-101, 1995.

Overheads and notes on lectures and seminars. SPRU, University of Sussex, 1997. (Technology and Development Course, MSc in Technology and Innovation Management Course). 
; Ross-Larson, B.; Westphal, L. E., Assessing the Performance of Infant Industries, Washington, DC: The World Bank, 1984. (World Bank Staff Working Papers, 666)

Bessant, J., "Developing Continuous Improvement Capability”, in International Journal of Innovation Management, 2(4): 409-29, 1998.

Brasil. MCT. Ciência, Tecnologia e Inovação: desafio para a sociedade brasileira - Livro Verde. Brasília: Ministério da Ciência e Tecnologia, Academia Brasileira de Ciências, 2001.

Livro Branco: Ciência, Tecnologia e Inovação. Brasília: Ministério da Ciência e Tecnologia, 2002

Chang, H-J., Kicking Away the Ladder - Development Strategy in Historical Perspective, Londres: Anthem Press, 2002.

Cohen, W. M.; Levin, R.C., "Empirical Studies Innovative Activity and Market Structure”, in Schmalensee, R.; Willig, R. (orgs.), Handbook of Industrial Organization, Amsterdã: North Holland, 1989.

; Levinthal, D.A., "Absorptive Capacity: a New Perspective on Learning and Innovation, in Administrative Science Quartely, 35 (1): 128-52, 1990.

Coutinho, Luciano G.; Ferraz, J. C.; Santos, A.; Veiga, P. M., Estudo da competitividade na indústria brasileira. [S.1.]: IE/Unicamp, FINEP, MCT, 1993.

Dahlman, C.; Ross-Larson, B.; Westphal, L. E., "Managing Technological Development: Lessons from the Newly Industrializing Countries", in World Development, v.15, n.6, p.75975, 1987.

; Westphal, L., "Technological Effort in Industrial Development: an Interpretative Survey of Recent Research", in Stewart, F.; James, J. (orgs.) The Economics of New Technology in Developing Countries, Londres: Frances Pinter, 1982. p.105-137.

Dosi, G., "Sources, Procedures, and Microeconomic Effects of Innovation", in Journal of Economic Literature, v.26, p.1.120-1.171, 1988a.

, "The Nature of the Innovative Process", in Dosi, G.; Freeman, C.; Nelson, R.; Silverberg, G.; Soete, L. (orgs.), Technical Change and Economic Theory, Londres: Pinter Publishers, 1988b.

Dutrénit, G., Learning and Knowledge Management in the Firm: from Knowledge Accumulation to Strategic Capabilities, Cheltenham, UK; Northampton, MA, USA: Edward Elgar Publishing, 2000.

Enos, J. L., The Creation of Technological Capability in Developing Countries, Londres: Pinter Publishers, 1991.

Ferigotti, C. M. F.; Figueiredo, P. N., "Aprendizagem tecnológica para acumulação de competências e inovação. O caso da Electrolux do Brasil S/A - Unidade Guabirotuba - 
Curitiba/PR", in X Seminário Latino-iberoamericano de Gestión Tecnológica, México D.F.. Anais do Y Seminário Latino-Iberoamericano de Gestión Tecnológica: Conocimiento, Innovación y Competitividad. Los desafios de la globalización, 2003.

Figueiredo, P. N., Technological Learning and Competitive Performance, Cheltenham, UK; Northampton, MA, USA: Edward Elgar Publishing, 2001.

"Does Technological Learning Pay Off? Implications for Inter-Firm Differences in Operational Performance Improvement”, in Research Policy, 31 (1), p.73-94, 2002. Aprendizagem tecnológica e performance competitiva. Rio de Janeiro: FGV, 2003 a. . Learning, capability accumulation and firms differences: evidence from latecomer steel. Industrial and Corporate Change, v. 12, n.3, p.607-643, 2003 b.

Gerschenkron, A., Economic Backwardness in Historical Perspective, Cambridge, MA: Harvard University Press, 1962.

Hobday, M., Innovation in East Asia: the Challenge to Japan, Aldershot: Edward Elgar, 1995. "Understanding Innovation in Electronics in Malaysia", in Jomo, K. S.; Felker, G.; Rasiah, R. (orgs.), Industrial Technology Development in Malaysia: Industry and Firm Studies, UK: Routledge, 1999.

Hollander, S., The Sources of Increased Efficiency: a study of Du Pont rayon plants. Cambridge, MA: MIT Press, 1965.

IEDI. Clusters ou Sistemas Locais de Produção Inovação: Identificação, Caracterização e Medidas de Apoio, São Paulo: IEDI, 2002

Gargalos da Indústria, São Paulo: IEDI, 2003.

Jacobsson, S.; Oskarsson, C., "Educational Statistics as an Indicator of Technological Activity", in Research Policy, 24, 127-36, 1995.

Kannebley, S. Jr., "Características das Firmas Inovadoras no Estado de São Paulo: uma Análise Empírica a Partir da PAEP”, Texto para discussão FEA-RP/USP, Série Economia, n.40, 2003.

Katz, J., Importación de Tecnología, Aprendizaje y Industrialización Dependiente, México: Fondo de Cultura Económica, 1976.

"Domestic Technological Innovations and Dynamic Comparative Advantages: Further Reflections on a Comparative Case-Study Program”, in Rosenberg, N.; Frischtak, C. (orgs.), International Technology Transfer: Concepts, Measures and Comparisons, Nova York: Praeger, 1985.

"Domestic Technology Generation in LDCs: a Review of Research Findings", in Katz, J. (org.), Technology Generation in Latin American Manufacturing Industries, Nova York: St Martin’s Press, 1987. 
Kim, L., Imitation to Innovation: The Dynamics of Korea's Technological Learning, Boston, MA: Harvard Business School Press, 1997.

Kumar, N., Siddharthan, N. S., Technology Market Structure and Internationalization: Issues and Policies for Developing Countries, Canadá: Federal Partners in Technology Transfer, National Research Council, 1997.

Lall, S., "Technological Learning in the Third World: Some Implications of Technology Exports", in Stewart, F.; James, J. (orgs.), The Economics of New Technology in Developing Countries. Londres: Frances Pinter, 1982.

Learning to Industrialise: the Acquisition of Technological Capability by India, Londres: Macmillan, 1987.

, “Technological Capabilities and Industrialization”, in World Development, v.20, n.2, p.165-86, 1992.

, “Technological Capabilities”, in Salomon, J. J. et al. (orgs.), The Uncertain Quest: Science Technology and Development, Tóquio: UN University Press, 1994.

Lee, J.; Bae, Z.-T.; Choi. D.-K., “Technology Development Processes: a Model for a Developing Country with a Global Perspective”, in R\&D Management, v.18, n.3, p.235-250, 1988.

Leornard-Barton, D., Wellsprings of Knowledge: Building and Sustaining the Sources of Innovation, Boston, MA: Harvard Business School Press, 1995.

Macedo, P. B. R.; Albuquerque, E. M., "P\&D e Tamanho da Empresa: Evidência Empírica sobre a Indústria Brasileira”, in Revista Estudos Econômicos, v.29, n.3, p.343-365, 1999.

Mani, S., Government, Innovation and Technology Policy: An Aanalysis of the Brazilian Experience During the 1990s. 2001. (UNU/INTECH, Discussion Papers Series, 2001-11)

Mansfield, E.; Teece, D.; Romeo, A., "Overseas Research and Development by US-Based Firms”, in Economica, May, v.46, p.187-196, 1979.

Marcovitch, J., "Política Industrial e Tecnológica no Brasil: uma Avaliação Preliminar", in Piensamento Iberoamericano, v.17, p.91-117, 1990.

Meyer-Stamer, J., "New Departures for Technology Policy in Brazil”, in Science and Public Policy, v.22, n.5, p.295-304, 1995.

Nicolsky, R., "Inovação Tecnológica Industrial e Desenvolvimento Sustentado”, in Parcerias Estratégicas, v.13, p.80-108, 2001.

OECD. Oslo Manual: Proposed Guidelines for Collecting and Interpreting Innovation Data, Paris: OECD: Statistical Office of the European Communities, 1997.

Pack, H., Productivity, Technology and Industrial Development: a Case Study in Textiles, Nova York: Oxford University Press, 1987.

Patel, P., "Localized Production of Technology for Global Markets", in Cambridge Journal of Economics, v.19, p.141-53, 1995. 
Pavitt, K., "Key Characteristics of the Large Innovating Firm”, in British Journal of Management, v.2, p.41-50, 1991.

, "Technology Transfer among the Industrially Advanced Countries: an Overview", in Rosenberg, N.; Frischtak, C. (orgs.), International Technology Transfer: Concepts, Measures, and Comparisons. Praeger Publishers, Nova York, 1985.

Penrose, E. T., The Theory of the Growth of the Firm, Oxford: Basil Blackwell, 1959.

Quadros, R.; Furtado, A.; Bernardes, R.; Franco, E., “Technological Innovation in Brazilian Industry: an Assessment Based on the São Paulo Innovation Survey”, in Technological Forecasting and Social Change, 67 (2-3): 203-219, jun., 2001.

Rosenberg, N., Inside the Black Box: Technology and Economics, Cambridge University Press, Cambridge, 1982.

, Perspectives on Technology, Cambridge University Press: Cambridge, 1976.

Salles-Filho, S., "Política de Ciência e Tecnologia no I PND (1972/74) e no I PBDCT (1973/74)", in Revista Brasileira de Inovação, v.1, n.2, p.397-419, 2002.

, "Política de Ciência e Tecnologia no II PBDCT (1976)", in Revista Brasileira de Inovação, v.2, n.1, p.179-211, 2003.

Salomon, J. J., "What is Technology? The Issue of its Origins and Definitions", in History and Technology, v.1, p.113-156, 1984.

Scott-Kemmis, D., "Learning and the Accumulation of Technological Capacity in Brazilian Pulp and Paper Firms", in World Employment Programme Research, 1988. (Working Paper, 187, p.2-22)

Staub, E., "Como Estimular o Investimento e Financiar o Crescimento", in Seminário "Políticas de Desenvolvimento”, Anais... São Paulo: FIESP/IEDI, 2002.

Tacla, C. L.; Figueiredo, P. N., "Processos de Aprendizagem e Acumulação de Capacidades Tecnológicas: Evidências de uma Empresa de Bens de Capital no Brasil, in Revista de Administração Contemporânea, v.7, n.3, p.101-126, 2003.

Tremblay, P., Comparative Analysis of Technological Capability and Productivity Growth in the Pulp and Paper Industry in Industrialised and Industrialising Countries. Thesis (D. Phil.), SPRU, Brighton: University of Sussex, 1994.

Utterback, J. M. Mastering the Dynamics of Innovation: How Companies can Seize Opportunities in the Face of Technological Change, Cambridge, MA: Harvard Bussiness School Press, 1994. 
Vedovello, C., Science Parks and the University-Industry Links: a Case Study of the Surrey Research Park. 1995. Thesis (PhD), SPRU, Brighton: University of Sussex, 1995.

, "Perspectivas e Limites da Interação entre Universidades e MPMEs de Base Tecnológica Localizadas em Incubadoras de Empresas”, in Revista do BNDES, v.8, n.16, p.281-316, dez., 2001.

, Godinho, M., "Business Incubator as a Technological Infrastructure for Supporting Small Innovative Firms' Activities”, in International Journal of Entrepreneurship and Innovation Management, v.3, n.1-2, p.4-21, 2003.

; Figueiredo, P. N., Implicaçôes da infra-estrutura tecnológica para o desenvolvimento de capacidades inovadoras nas indústrias eletroeletrônica, de duas rodas e seus principais fornecedores: construção de base de competitividade para o Pólo Industrial de Manaus, Perspectiva 2020. Rio de Janeiro: Programa de Pesquisa em Aprendizagem Tecnológica e Inovação Industrial no Brasil, Ebape/FGV, 2003, (Relatório Final).

Westphal, L. E.; Kim, L.; Dahlman, C. J., Reflections of Korea's Acquisition of Technological Capability, Washington, DC: World Bank Research Department, Economics and Research Staff, 1984. (Report DRD77)

Wortman, M., "Multinationals and the Internationalisation of R\&D: New Developments in German Companies”, in Research Policy, 19, 175-83, 1990. 